Article

\title{
Phytosomes with Persimmon (Diospyros kaki L.) Extract: Preparation and Preliminary Demonstration of In Vivo Tolerability
}

\author{
Rosa Direito ${ }^{1}\left(\mathbb{D}\right.$, Catarina Reis ${ }^{1, *(\mathbb{D})}$, Luís Roque ${ }^{2}$, , Margarida Gonçalves ${ }^{3}$, \\ Ana Sanches-Silva ${ }^{4,5}$, Maria Manuela Gaspar ${ }^{1}$, Rui Pinto ${ }^{1,6} \mathbb{D}^{\mathbb{D}}$, João Rocha ${ }^{1}$, Bruno Sepodes ${ }^{1} \mathbb{D}$, \\ Maria Rosário Bronze ${ }^{1,7,8}$ and Maria Eduardo Figueira ${ }^{1}$ \\ 1 Research Institute for Medicines (iMed.ULisboa), Faculty of Pharmacy, Universidade de Lisboa, \\ 1649-003 Lisbon, Portugal; rdireito@ff.ulisboa.pt (R.D.); mgaspar@ff.ulisboa.pt (M.M.G.); \\ rapinto@ff.ulisboa.pt (R.P.); jrocha@ff.ulisboa.pt (J.R.); bsepodes@ff.ulisboa.pt (B.S.); \\ mrbronze@ff.ulisboa.pt (M.R.B.); efigueira@ff.ulisboa.pt (M.E.F.) \\ 2 Department of Biomedical Sciences, Faculty of Pharmacy, University of Alcalá, Ctra. Universidad \\ Complutense, 28871 Alcalá de Henares, Spain; luis_roque_10@hotmail.com \\ 3 Departamento de Ciências e Tecnologia de Biomassa, Mechanical Engineering and Resource Sustainability \\ Centre, Faculdade de Ciências e Tecnologia, UNL, Quinta da Torre, 2829-516 Monte da Caparica, Portugal; \\ mmpg@fct.unl.pt \\ 4 National Institute for Agricultural and Veterinary Research (INIAV), Vairão, 4485-655 Vila do Conde, \\ Portugal; anateress@gmail.com \\ 5 Centre for Study in Animal Science (CECA), ICETA, University of Oporto, 4099-002 Oporto, Portugal \\ 6 JCS, Dr. Joaquim Chaves, Laboratory of Clinical Analysis, 1495-068 Lisbon, Portugal \\ 7 ITQB, Estação Agronómica Nacional, Av. da República, 2780-157 Oeiras, Portugal \\ 8 IBET, Avenida da República, Quinta-do-Marquês, Estação Agronómica Nacional, 2780-157 Oeiras, Portugal \\ * Correspondence: catarinareis@ff.ulisboa.pt; Tel.: +351-21-794-6400 (ext. 14244)
}

Received: 1 May 2019; Accepted: 20 June 2019; Published: 22 June 2019

\begin{abstract}
Persimmon (Diospyros kaki L.), a fruit rich in phenolic compounds (PCs), has been considered effective in mitigating oxidative damage induced by an excess of reactive oxygen species. Due to large molecular weight and intrinsic instability in some physiological fluids, PCs' passage through biological membranes is very limited. Carriers like phytosomes are promising systems to optimize oral absorption of encapsulated extracts. This work prepared and fully characterized phytosomes containing bioactive phenolic extracts from persimmon in terms of size, surface charge, encapsulation efficiency and stability over six months. These phytosomes were orally dosed to Wistar rats during a 15-day period. Afterwards, haematological and biochemical analyses were performed. Monodisperse phytosomes were successfully prepared, with size less than 300nm $(\mathrm{PI}<0.3)$ and high encapsulation efficiency $(97.4 \%)$ of PCs. In contrast to free extract, extract-loaded phytosomes had higher antioxidant activity after 6 months storage. Oral administration of extract-loaded phytosomes and free extract did not lead to lipidic profile changes and were within referenced normal ranges, as well as glycaemia levels and urine parameters. The results highlighted the potential of persimmon PCs as food supplements or pharmacological tools, suggesting a promising and safe phytosomal formulation containing bioactive agents of persimmon that could lead to health benefits.
\end{abstract}

Keywords: Persimmon; Diospyros kaki; phenolic compounds; phytosomes; food supplement; antioxidant; encapsulation efficiency; in vivo assessment 


\section{Introduction}

Recent literature reviews have shown that the majority of bioactive compounds used in modern therapeutics, about $90 \%$ of them, had natural origins, i.e., they are derived from natural products or their chemical structure was inspired by natural products [1].

In the case of dietary supplements, nutraceuticals, and functional foods based on natural products, their use is increasing in order to answer growing consumer demand. However, more evidence is necessary about their health benefits and possible risks, in order to guarantee safety and effectiveness. This study provides a contribution to a new delivery system of a $D$. kaki's extract with the potential to exert health benefits. Several examples of phytochemical extracts of fruits and vegetables (which have strong antioxidant and anti-proliferative activity) have been described in current literature, where the combination of phytochemicals accounted for most of their total antioxidant activity. The additive and synergistic effects of phytochemicals on fruits and vegetables were responsible for their potent antioxidant activities [2].

The Ebenaceae family has more than 350 known species, one of which is the Diospyros genus [3]. This genus is prevalent Japan, China, and Korea, but it is in the latter two countries that Persimmon (Diospyros kaki L.) is traditionally used for medicinal purposes [4] for their positive effects on human health. Several different studies have reported pharmacological activities and the phytoconstituents profile of various parts of this plant [5-7]. Many studies showed that persimmon extract and its constituents have potent antitumor activity against human cancer cells. Even though their molecular mechanisms are not yet fully comprehended, some studies have shown that 24-hydroxyursolic acid, a triterpenoid found in persimmon, activated AMP-activated protein kinase (AMPK), inhibited cyclooxygenase (COX-2) expression in HT-29 cells, and induced cellular apoptosis by activation of poly (ADP-ribose) polymerase (PARP), caspase-3, and phosphorylation of p53 at Ser15. It also strongly induced DNA fragmentation in HT-29 cells and thereby significantly inhibited colony formation of HT-29 cells in soft agar [8]. In vitro studies also demonstrated that persimmon phenolic extract successfully impaired cell proliferation and invasion in HT-29 cells. The exposure to 250, 500, 1000 and $2000 \mu \mathrm{g} / \mathrm{mL}$ of persimmon phenolic extracts lowered the ability of HT-29 cells to invade the wound gap, in a dose-dependent manner and the highest concentration used $(2000 \mu \mathrm{g} / \mathrm{mL})$ in the study, was quite effective in inhibiting cell migration, reducing it to close to zero [9]. Further in vivo investigation in a model of colitis in mice administered with persimmon phenolic extract, showed decreased levels of expression of COX-2 and inducible nitric oxide synthase (iNOS) in the colonic tissue, these being two important mediators of intestinal inflammation, but there was no inhibition of gelatinase MMP-9 and MMP-2 activities. Given the important link between inflammation and cancer and growing evidence suggesting a role for inflammatory processes in the progression of colorectal cancer, these results highlighted the potential of persimmon polyphenols as a pharmacological tool in the treatment of patients with inflammatory bowel diseases (IBD) [9]. Accordingly, due to certain bioactive molecules like proanthocyanidins, carotenoids, tannins, flavonoids, anthocyanidin, catechin, and so forth, persimmon is considered effective in mitigating oxidative damage induced by reactive oxygen species (ROS). It should be noted that this has helped in preventing oxidation of low-density lipoproteins, in preserving the function of beta pancreatic cells, and reducing the progression of cardiovascular diseases, cancer, diabetes mellitus, and cell damage caused by external agents, such as the damage associated to chronic alcohol consumption [9-11].

However, the authors agreed that some characteristics of these phytoconstituents might limit their bioavailability, such as low solubility in aqueous media and/or low permeability of their passage through biological membranes and the intrinsic instability of these molecules in some physiological fluids [12]. However, the administration of these phytoconstituents is known to produce quantifiable pharmacodynamic effects even in the absence of pharmacokinetic determinations (e.g., bioavailability).

Nevertheless, new drug delivery strategies, such as Phytosomes ${ }^{\circledR}$ (Indena, Milan, Italy), have demonstrated numerous advantages to overcome these limitations $[13,14]$. The encapsulation of these bioactive compounds into nanosystems has been widely accepted to be a promising strategy for 
the optimization of their functional or pharmacological activity after oral administration [15-17] and, in some cases, to improve their safety $[16,18,19]$. This green nanotechnology, in phytoformulations, significantly contributes to environmental sustainability through the production of nanoproducts, without causing harm to human health or the environment.

The health preventive potential of nutraceuticals is a current focus of the health-care industry given a change in paradigm within the system, shifting its principal approach from treatment to prevention. In order to guarantee compliance for the long-term use of nutraceuticals, designing oral delivery systems has become crucial for success. It is acknowledged that the use of the oral route of administration, however, is limited by the problem of low bioavailability from the gastrointestinal (GI) tract and in vivo stability of many of the nutraceuticals, for example, enzymes, certain antioxidants, vitamins, and phytoconstituents.

This study described the production of phytosomes containing a bioactive extract of Diospyros $k a k i \mathrm{~L}$. based on three important requisites for their future application-high quality of a future dosage form with the potential to demonstrate efficacy and tolerability when used in humans as an add-on to the existing therapeutic options. Alongside with the preparation of phytosomes, a preliminary characterisation of tolerability after repeated dose oral administration in a rodent model was performed.

\section{Materials and Methods}

\subsection{Materials, Solvents and Reagents}

Phosphatidylcholine (48\% purified from soy lecithin), 2,2-diphenyl-1-picrylhydrazyl (DPPH), Folin \& Ciocalteu's phenol reagent and quercetin $3-\beta$-glucoside $(\geq 90 \%$ pure) were purchased from Sigma-Aldrich, Co (St. Louis, MO, USA). Acetic acid was purchased from Panreac (Barcelona, Spain). Anhydrous sodium carbonate was obtained from VWR ${ }^{\circledR}$ Prolabo ${ }^{\circledR}$, VWR International. Gallic acid (98\%) was acquired from Merck (Darmstadt, Germany) and methanol (99.9\%) was bought from Carlo Erba Reagents (Rodano, Italy). The study made use of Milli- $Q^{\circledR}$ water $(18.2 \mathrm{M} \Omega \mathrm{cm})$ which was attained from a Millipore-Direct Q3 UV System (Molsheim, France). Chromatography solvents are HPLC grade (Merck, Darmstadt, Germany) and the remaining reagents were analytical grade.

The materials for UHPLC-DAD: Merck ${ }^{\circledR}$ gradient grade methanol; acetic acid (glacial) RPE from Carlo Erba; ultrapure water.

Standards UHPLC-DAD: A number of selected phenolic compounds that were used as standards were procured from Sigma-Aldrich ${ }^{\circledR}$ (Madrid, Spain), namely: Protocatechuic acid (CAS 99-50-3); gallic acid (CAS 149-91-7); chlorogenic acid (CAS 329-97-9),;caffeic acid (CAS 331-39-5); epicatechin (CAS 490-46-0); ferulic Acid (CAS 1135-24-6); p-coumaric (CAS 7400-08-0); catechin (CAS 88191-48-4); and fisetin (CAS 345909-34-4); all from Sigma-Aldrich. The purity of the standards was always greater than $95 \%$.

Sticks URIT 10V were purchased from Quilaban LDA (Quilaban LDA, Sintra, Portugal).

Ketamine (Imalgene ${ }^{\circledR}$ 1000) was purchased from Merial (Lisbon, Portugal), and xylazine (Rompun ${ }^{\circledR} 2 \%$ ) was purchased from Bayer (Lisbon, Portugal).

\subsection{Equipments}

The Vötsch Industrietechnik heating chamber, VC2033 mit TC-Steuerung; Centrifuge 5804 R from Eppendorf (Hamburg, Germany); Rotavapor R-210 from Buchi (Meierseggstrasse, Switzerland; magnetic stirrer (HTS 1003, LMS, Tokyo, Japan); UV-vis spectrophotometer, Hitachi L-2000 (Hitachi High Technology, Tokyo, Japan); Millipore ${ }^{\circledR}$ water system $\left(18.2 \Omega \mathrm{cm}\right.$ at $\left.25{ }^{\circ} \mathrm{C}\right)$ was purchased from Millipore-Direct Q3 UV System equipment (Molsheim, France); Delsa Nano C (Coulter, CA, USA); scanning electron microscopy (SEM 5200LV, JEOL, Tokyo, Japan) to evaluate morphology. A HPLC-DAD system (SpectraSystem, Thermo, Darmstadt, Germany) equipped with a binary gradient pump (SpectraSystem P2000, Thermo, Darmstadt, Germany), automatic sampler (SpectraSystem AS1000, Thermo, Darmstadt, Germany), diode array detector (SpectraSystem UV6000LP, Thermo, 
Darmstadt, Germany), UV controller (SpectraSystem SN4000, Thermo, Darmstadt, Germany) and software Xcalibur ${ }^{\mathrm{TM}}$ 2.0.6 (Thermo Fisher Scientific Corporation, Waltham, MA, USA) was used as well as an UHPLC Acquity ${ }^{\mathrm{TM}}$ (Waters, Milford MA, USA) equipped with a binary pump, an auto-sampler binary solvent manager, a column thermostatting system and a diode array detector (DAD).

\subsection{Methods}

\subsubsection{Vegetal Extract Preparation}

The fruit used in this study, Persimmon (Diospyros kaki L.), was acquired from a cultivar grown in Portuguese territory (Setúbal region). The extract of persimmon fruit was prepared via the union of a number of methods described [20,21] albeit with some adjustments. Approximately $360 \mathrm{~g} \pm 0.1 \mathrm{~g}$ of fresh persimmon fruit (FW) was extracted without calyx, using acetone:water $(80: 20, v / v)$ and it was then mechanically homogenized for $10 \mathrm{~min}$ (at room temperature and protected from light). The extracted sample was then centrifuged at $8603 \times g$ for $10 \mathrm{~min}$ at room temperature (Eppendorf centrifuge $5804 \mathrm{R}$ (Hamburg, Germany). The supernatant was then collected, and the pellet was extracted three more times using this same procedure. The supernatants were collected together and filtered, the sample was evaporated to almost dryness $\left(35^{\circ} \mathrm{C}\right.$, with slow, adjustable rotation), and finally, the extract was made up of Milli-Q ${ }^{\circledR}$ water $(240 \mathrm{~mL})$ with at least $1.5 \mathrm{~g} \mathrm{FW} / \mathrm{mL}$ to encapsulate. The extract obtained was subsequently subdivided into aliquots and it was stored in falcon tubes at $-20^{\circ} \mathrm{C}$, for further analysis.

\subsubsection{Quantification of the Total Polyphenolic Content}

The procedure to quantify total phenolic content determination was based on a previous work [22]. An aliquot of the sample with $100 \mu \mathrm{L}$ was added to $200 \mu \mathrm{L}$ of Folin-Ciocalteau reagent (diluted in water at $1: 10, v / v)$ where after $3 \mathrm{~min}, 1 \mathrm{~mL}$ of sodium carbonate $(15 \%, w / v)$ and $2 \mathrm{~mL}$ of water were added. After incubating at room temperature for one hour, the absorbance was measured in the UV-Visible spectrophotometer at $765 \mathrm{~nm}$ (Hitachi L-2000, Hitachi High Technology, Tokyo, Japan) against a blank, i.e., a mixture of water and reagents.

A calibration curve of gallic acid was performed in a concentration range from 2 to $500 \mathrm{mg} / \mathrm{L}$. The results were expressed in milligrams of gallic acid equivalents (mg of GAE) per $100 \mathrm{~g}$ of fresh fruit and per millilitre of extract. The determinations were made in triplicate and results were expressed as the means $\pm \mathrm{SD}$.

\subsubsection{Quantification of D. kaki Phenolic Compounds in Extract and Non-Encapsulated PCs by} Liquid Chromatography

An Ultra High Performance Liquid Chromatographic (UPLC ${ }^{\circledR}$, Acquity ${ }^{\mathrm{TM}}$, Waters, Milford, MA, USA) method coupled with a diode array detector (UHPLC-DAD) was developed for simultaneous quantification of the main phenolic compounds of the persimmon extract. The pre-column was an Acquity ${ }^{\mathrm{TM}} \mathrm{UPLC}^{\circledR}$ BEH C18 $(2.1 \mathrm{~mm} \times 5 \mathrm{~mm}, 1.7 \mu \mathrm{m}$ particle size $)$. The column was an Acquity ${ }^{\mathrm{TM}}$ $\mathrm{UPLC}^{\circledR}$ BEH C18 RP $18(2.1 \mathrm{~mm} \times 50 \mathrm{~mm}$, particle size $1.7 \mu \mathrm{m})$. The mobile phase was a gradient of water with $0.1 \%$ acetic acid $(v / v)$ (solvent $\mathrm{A}$ ) and acetonitrile with $0.1 \%(v / v)$ acetic acid (solvent $\mathrm{B}$ ). The mobile phase gradient was: $0 \mathrm{~min}, 10 \%$ of solvent $\mathrm{B} ; 2.5 \mathrm{~min} 15 \%$ of solvent $\mathrm{B} ; 10 \mathrm{~min}, 30 \%$ of solvent $\mathrm{B} ; 10.5 \mathrm{~min}, 30 \%$ of solvent $\mathrm{B} ; 12 \mathrm{~min} 10 \%$ of solvent $\mathrm{B}$.

The temperature of the analytical column was $20^{\circ} \mathrm{C}$ and the samples were kept at $5{ }^{\circ} \mathrm{C}$ until analysed. The injection volume was $10 \mu \mathrm{L}$ and the flow of the mobile phase was $0.2 \mathrm{~mL} / \mathrm{min}$. In order to correctly identify each compound, specificity was evaluated by comparing the absorption spectra of the chromatographic peaks obtained from the sample with the absorption spectra of analytical standards $[23,24]$. The quantification of the compounds was performed based on the peak area at a characteristic maximum absorption spectrum $\left(\lambda_{\max }\right)$ and the corresponding retention time $\left(\mathrm{R}_{\mathrm{t}}\right)$ of each phenolic compound. The data was acquired using the software Empower ${ }^{\mathrm{TM}}$ version 2.0 (Waters, Milford, MA, USA). The analyses were performed in triplicate. 
The chromatographic separation by high-performance liquid chromatography (HPLC) was performed on a reverse phase $C_{18}$ column (Thermo Scientific) with a particle diameter of $5 \mu \mathrm{m}$ and a length of $15 \mathrm{~cm}$. The acquisition of chromatograms and UV-Vis spectra was performed using the software Xcalibur ${ }^{\mathrm{TM}}$ 2.0.6 (Thermo Fisher Scientific Corporation, Waltham, MA, USA), scanning between 190 and $700 \mathrm{~nm}$, with a range of $1 \mathrm{~nm}$ and also at the specific lengths of 280 and $360 \mathrm{~nm}$. The injection volume was $20 \mu \mathrm{L}$. The mobile phase consisted of Milli- ${ }^{\circledR}$ water-phosphoric acid (99.9: $0.1, v / v)$ as eluent $\mathrm{A}$, and Milli- $\mathrm{Q}^{\circledR}$ water-acetonitrile-phosphoric acid $(59.9: 40.0: 0.1, v / v / v)$ as eluent $\mathrm{B}$. The mobile phase gradient was: From $0-15$ min was from $0 \%$ to $20 \%$ of solvent $B ; 10$ min with $20 \%$ solvent $\mathrm{B} ; 25-70 \mathrm{~min}$, from $20 \%$ to $70 \%$ solvent $\mathrm{B} ; 70-75 \mathrm{~min}$, with $70 \%$ of solvent $\mathrm{B} ; 75-85 \mathrm{~min}$ from $70 \%$ to $100 \%$ solvent $B ; 85-110$ min, with $100 \%$ solvent $B ; 111-120$ min $100 \%$ of solvent $A$. The flow rate was $0.7 \mathrm{~mL} / \mathrm{min}$. Xcalibur ${ }^{\mathrm{TM}}$ software version 2.0.6 (Thermo Fisher Scientific Corporation, Waltham, MA, USA) was used to acquire and process the data. The identification of compounds was done by comparing the retention time $\left(\mathrm{R}_{\mathrm{t}}\right)$, spectra and spiking samples with pure standard solutions, whenever available, or comparing with data from the literature.

An aliquot of the concentrated extract was diluted (1:7) in Milli-Q water to a concentration equal to the one present in the formulation and was analysed using the method and assay conditions described above. The compounds present in the supernatant of the formulation were identified by comparing and overlapping of the chromatograms obtained for the extract.

\subsubsection{Preparation of Standard Stock Solutions and Work Solutions}

From each compound, stock solutions at $5 \mathrm{mg} / \mathrm{mL}$ were prepared, except for protocatechuic acid with $2 \mathrm{mg} / \mathrm{mL}$. The dilutions (1:100) of those stock solutions were performed with acidified $50 \%$ methanol ( $0.1 \%$ acetic acid) and filtered with a $0.2 \mu \mathrm{m}$ filter. Several standard concentrations were then prepared: Gallic acid $(50 \mu \mathrm{g} / \mathrm{mL})$; chlorogenic acid $(125 \mu \mathrm{g} / \mathrm{mL})$; caffeic acid $(50 \mu \mathrm{g} / \mathrm{mL})$; epicatechin $(125 \mu \mathrm{g} / \mathrm{mL}) ;$-coumaric acid $(50 \mu \mathrm{g} / \mathrm{mL}) ;$ ferulic acid $(75 \mu \mathrm{g} / \mathrm{mL}) ;(+)$-catechin $(150 \mu \mathrm{g} / \mathrm{mL})$; fisetin $(50 \mu \mathrm{g} / \mathrm{mL})$ and protocatechuic acid $(50 \mu \mathrm{g} / \mathrm{mL})$. To this mixture, $6.8 \mathrm{~mL}$ of methanol was added and the volume of the volumetric flask was made up to $20 \mathrm{~mL}$ with ultrapure water with $0.2 \%$ acetic acid. Subsequently, approximately $2 \mathrm{~mL}$ of the solution was filtered into vial with $0.2 \mu \mathrm{m}$ filter and individually injected into the UHPLC-DAD.

The order of elution of phenolic compounds was observed in the chromatogram corresponding to the mix solution. For each phenolic compound, the characteristic maximum absorption spectrum $\left(\lambda_{\max }\right)$ and the retention time $\left(\mathrm{R}_{\mathrm{t}}\right)$ was determined [25].

\subsubsection{Sample}

The persimmon extract solution was prepared with $1.5 \mathrm{~mL}$ of mature persimmon extract in a $10 \mathrm{~mL}$ volumetric flask and the volume of each flask was completed with acidified $50 \%$ methanol $(0.1 \%$ acetic acid). Approximately, $2 \mathrm{~mL}$ of this sample solution was filtered for vials with $0.2 \mu \mathrm{m}$ filters, for further analysis in UHPLC. The results were expressed in $\mathrm{mg} / 100 \mathrm{~g}$ of fresh fruit.

\subsubsection{Phytosomes Preparation}

Phytosomes were prepared by adding extract to phosphatidylcholine dissolved in $20 \mathrm{~mL}$ of ethanol (1:1 or 1:2, molar ratio). This mixture was heated to $25^{\circ} \mathrm{C}$ with a rotation of $300 \mathrm{rpm}$ (HTS 1003, LMS, Tokyo, Japan) for $2 \mathrm{~h}$. Thereafter, $40 \mathrm{~mL}$ of $2 \%$ acetic acid solution was added, and the mixture remained for $24 \mathrm{~h}$ in the same conditions previously described by Matias et al. 2015 [26].

\subsubsection{Physical Characterization of Phytosomes}

The phytosomes were diluted (1:10) with distilled water and analysed on a Delsa Nano C (Coulter, CA, USA). The mean particle size, polydispersity index (PI) and zeta potential ( $\zeta \mathrm{P})$ were evaluated at room temperature using detection angle of $165^{\circ}$ (except for zeta potential at $90^{\circ}$ ) for samples of the 1:1 and 1:2 formulation after 0,3 and 6 months of preparation. 


\subsubsection{Determination of Encapsulation Efficiency (EE)}

The efficiency of encapsulation (EE, \%) of the extract in the phytosomes was determined by evaluating the fraction of the non-encapsulated extract [27]. After centrifugation, the supernatant was collected and analysed on HPLC-DAD. Briefly, $2 \mathrm{~mL}$ aliquot of the phytosomal formulation was added to $2 \mathrm{~mL}$ oil and homogenized. Then, it was centrifuged at 15,000 $\mathrm{g}$ (Eppendorf centrifuge $5804 \mathrm{R}$ (Hamburg, Germany) for $30 \mathrm{~min}$ at $4{ }^{\circ} \mathrm{C}$. The lower phase was separated and filtered with a $0.22 \mu \mathrm{m}$ filter (VWR ${ }^{\mathrm{TM}}$, Radnor, PA, USA) and injected for HPLC chromatographic analysis. A blank was prepared in the same manner but with $2 \mathrm{~mL}$ water and $2 \mathrm{~mL}$ oil. The encapsulated extract (\%) was calculated by the difference between the total persimmon extract area (corresponding to the extract added to the formulation) and the total chromatogram area of the supernatant (corresponding to non-encapsulated phenolic compounds) [26,28-30]. Applying Equation (1), the encapsulation efficiency (EE, \%) of the extract in the phytosomes was determined at 280 and $360 \mathrm{~nm}$. Independent injections into the HPLC column were performed and analysed.

$$
\mathrm{EE}(\%)=\frac{\mathrm{W}(\text { added extract })-\mathrm{W}(\text { free extract in supernatant })}{\mathrm{W}(\text { added extract })} \times 100
$$

The total phenolic compounds in the supernatant were also calculated by the spectrophotometric $(765 \mathrm{~nm})$ quantification of total phenolic compounds by the Folin-Ciocalteu technique. The same calculation was made for the extract sample and the encapsulation efficiency (EE, \%) of the extract in the phytosomes was also calculated according to Equation (1). All measures were performed in triplicate.

\subsubsection{Stability Test over the Time}

The objective of the stability study was to evaluate the stability based on the test of at least three batches of the formulation following international guidelines [31]. Stability studies should include testing of those attributes of the bioactive compounds that are susceptible to change during storage and are likely to influence quality, safety, and/or efficacy [31,32].

Parameters like particle size, PI and zeta potential were accessed over time.

\subsubsection{Storage Conditions}

In general, a consumer product should be evaluated under storage conditions (with appropriate tolerances) and, if applicable, its sensitivity to moisture or potential for loss of solvent. The storage conditions and duration of the chosen studies should be sufficient to cover the storage, transport, shipping and subsequent use [31].

In an intermediate stability study, the minimum time period covered by data at submission was 6 months and the storage conditions generally were $30 \pm 2{ }^{\circ} \mathrm{C} / 65 \% \mathrm{RH}$ (relative humidity) $\pm 5 \% \mathrm{RH}$ [32].

The accelerated storage conditions of the study were: $40 \pm 2{ }^{\circ} \mathrm{C} / 75 \% \mathrm{RH} \pm 5 \% \mathrm{RH} ; 25 \pm 2{ }^{\circ} \mathrm{C} / 60 \%$ $\mathrm{RH} \pm 5 \% \mathrm{RH}$ and $4 \pm 2{ }^{\circ} \mathrm{C}$, over a period of 6 months. In the accelerated storage condition, a minimum of three points in time, including the start and end time points (for example, 0, 3 and 6 months), of a 6-month period study was recommended [32].

\subsubsection{Closure System and Container}

Stability studies were conducted by storing the concentrated polyphenolic extract in a container and closure system, which was the same as the proposed packaging for storage and distribution [31].

The two formulations (1:1 and 1:2, molar ratio) with $30 \mathrm{~mL}$ were each stored for 6 months in glass amber type II colour bottles and sheltered from light at room temperature $\left(\sim 25^{\circ} \mathrm{C}\right)$ and $60 \% \mathrm{RH}$, in the refrigerator at $4{ }^{\circ} \mathrm{C}$ and $55 \% \mathrm{RH}$ and at $40{ }^{\circ} \mathrm{C}$ in a heating chamber (Vötsch Industrietechnik, VC2033 mit TC-Steuerung, Oldenburg, Germany) with $75 \%$ humidity. At the same time, aliquots ( $7 \mathrm{~mL}$ ) of the concentrated extract as well as quercetin standard solutions $(10 \mathrm{~mL})$ were also placed under the same conditions as the above-mentioned formulations. 


\subsubsection{Determination of the Antioxidant Activity}

The potential for elimination of free radicals by the extract and by the phytosomal formulation (1:1 and 1:2) was determined according to the previous procedure [33]. In brief, aliquots of $10 \mu \mathrm{L}$ of each sample were mixed with $990 \mu \mathrm{L}$ of DPPH solution $(0.002 \%$ in $70 \%$ ethanol). The reaction mixture was incubated at room temperature for $30 \mathrm{~min}$ in the dark. The positive control was quercetin at $10 \mathrm{mgmL}^{-1}$ in water. As the absorbance control (i.e., at $100 \%$ ), a sample containing $10 \mu \mathrm{L}$ water and $990 \mu \mathrm{L}$ DPPH was prepared. The free radical scavenging potential of the 1:1 and 2:1 phytosomal formulation and free extract samples were expressed as the disappearance of the initial purple colour. The absorbance was measured at $517 \mathrm{~nm}$ against a blank sample of 70\% ethanol using a UV-Visible Spectrophotometer (Hitachi L-2000 from Hitachi High Technology, Tokyo, Japan). Each sample was tested in triplicate $(n=3$; mean $\pm \mathrm{SD})$. The sequestration capacity of DPPH was calculated using the following formula (2):

$$
\text { Scavenging activity }(\%)=\frac{\text { Absorbance control }- \text { Absorbance sample }}{\text { Absorbance control }} \times 100
$$

\subsubsection{In Vivo Safety Assessment}

Four-month-old female Wistar rats (250-330 g), obtained from Charles River (Barcelona, Spain) were housed in a 12-12 h light-dark cycle with a constant temperature environment of around $22{ }^{\circ} \mathrm{C}$ and a relative humidity of $55 \%$. Animals were allowed free access to food and water during acclimatization. All animal experiments were conducted according to the animal welfare organ of the Faculty of Pharmacy, Universidade de Lisboa, approved by the competent national authority Direção-Geral de Alimentação e Veterinária (DGAV) and in accordance with the EU Directive (2010/63/UE) and Portuguese laws (DR 113/2013, 2880/2015 and 260/2016).

Animals were randomly allocated into three experimental groups: The sham group which were dosed with distilled water $(n=3)$; test group with animals orally dosed with extract-loaded phytosomes $(15 \mathrm{mg} / \mathrm{kg})(n=5) ;$ and the free extract group $(n=5)$ where the same dose of the extract was applied. Oral administrations were performed daily, during the 15 days of the protocol, by gastric gavage. During the 15-day experiment, weight and mortality of all animal groups were monitored. The clinical signs of each rat were examined for ataxia, dehydration, dyspnoea, hypothermia, tachypnoea, lack of movement, sustained rapid movement around the cage, seizure, hunched posture and ruffled fur. A scale of 0 to 3 was used by an investigator blinded to treatment groups, where 0 was used for no indication, 1 for minimal indication, 2 for critical indication, and 3 for extreme indication of clinical problem(s).

Glycaemia was measured three times during the 15-day assay, at day 0, at the end of the first week of administration, and at day 15 of the protocol. All measures were done in triplicate in each of the three times of the protocol.

For the analysis of urine parameters, urine of all animal groups was collected on days 0,7 and 15 and urine density, $\mathrm{pH}$, bilirubin, urobilinogen, blood, glycosuria, proteinuria and ketonic bodies, leucocytes and nitrites were analysed using Sticks URIT 10V (Quilaban LDA, Sintra, Portugal). All measures were done in triplicate in each of the three times of the protocol.

After 15 days, animals were anaesthetised, blood and urine were collected for analysis and then sacrificed.

The evaluation of biochemical and haematological parameters was performed on the blood and serum of all animals. The blood was taken via cardiac puncture, where whole blood was collected into two tubes containing ethylenediaminetetraacetic acid (EDTA) as an anticoagulant. For haematological analysis, the parameters examined were: Mean corpuscular volumes (MCV); mean corpuscular haemoglobin $(\mathrm{MCH})$; mean corpuscular haemoglobin concentrations (MCHC); neutrophils (NEU, \%); basophils (BAS, \%); eosinophils (EO, \%); monocytes (MO, \%) and lymphocytes (LYM, \%); erythrocyte counts (RBC); leukocyte counts (WBC); haematocrit, haemoglobin ( $\mathrm{Hb})$; and platelets (Coulter MaxM, 
Beckman Coulter, High Wycombe, UK). Another part of the blood was collected into tubes without EDTA and was centrifuged after coagulation (2500× $g$ during $10 \mathrm{~min}$ ). The serum was analysed by an automated clinical chemistry analyser (ADVIA ${ }^{\circledR} 1200$, Synchron CX4, Beckman Coulter, Bucks, UK). Biochemical parameters analysed were cholesterol (CHOL), low density lipoprotein (LDL), high density lipoprotein (HDL), alanine aminotransferase (ALT), alkaline phosphatase (ALP), aspartate aminotransferase (AST), triglycerides (TRIG), urea (UR), total proteins (T-PROT), and creatinine (CR). The results of each tested parameter have been presented for each group of rats as the mean \pm SD.

\subsubsection{Statistical Analysis}

The results were expressed as the means \pm standard deviations (SD). An analysis of variance with ANOVA test was applied. For multiple comparison group tests, Tukey's or Dunnett's multi-comparison test was applied, using Graph Prisma Version 6.01 (GraphPad Software, San Diego, CA, USA). The differences were considered statistically significant when $p<0.05$.

\section{Results}

\subsection{Quantification of the Total Phenolic Content of D. kaki}

The Folin-Ciocalteau method was performed using gallic acid as standard and a range from 2-500 $\mathrm{mg} / \mathrm{L}$ was considered linear $\left(R^{2}=0.9868\right)$ and was used to determine the concentration of total phenolic compounds in the extract prepared for this work. The results are presented in Table 1.

Table 1. The concentration of total PCs.

\begin{tabular}{ccc}
\hline \multirow{2}{*}{ Sample } & \multicolumn{2}{c}{ [Phenolic Compounds] } \\
\cline { 2 - 3 } & mg GAE/L & mg GAE/100g FW \\
\hline Extract & $9620 \pm 779.4$ & $641 \pm 51.96$ \\
\hline Added extract & $1112 \pm 34.6$ & - \\
\hline Supernatant & $70.9 \pm 4.9$ & - \\
\hline
\end{tabular}

\subsection{Quantification of the Phenolic Compounds in Extract of D. kaki by UHPLC-DAD}

The concentrations of the phenolic compounds (gallic acid, protocatechuic acid, chlorogenic acid, catechin, caffeic acid, epicatechin, $p$-coumaric acid, ferulic acid and fisetin) were determined by the UHPLC-DAD methodology. The retention time $\left(R_{t}\right)$ and the characteristic maximum absorption wavelength $\left(\lambda_{\max }\right)$ of each phenolic compound were determined. This method allowed for the detection and quantification of the phenolic compounds at low concentrations (LOD $<0.125 \mu \mathrm{g} / \mathrm{mL}$, except for catechin which presented a LOD of $0.3 \mu \mathrm{g} / \mathrm{mL}$ ) as described in Table 2.

Table 2. Calibration curves for 9 PCs.

\begin{tabular}{cccccccc}
\hline PC & $\begin{array}{c}\mathbf{R}_{\mathbf{t}} \\
(\mathbf{m i n})\end{array}$ & $\begin{array}{c}\lambda_{\mathbf{m a x}} \\
(\mathbf{n m})\end{array}$ & $\begin{array}{c}\text { Working Range } \\
(\boldsymbol{\mu} \mathbf{g} / \mathbf{m L})\end{array}$ & Curve Equation & $\boldsymbol{R}^{\mathbf{2}}$ & $\begin{array}{c}\text { LOQ } \\
(\boldsymbol{\mu g} / \mathbf{m L})\end{array}$ & $\begin{array}{c}\mathbf{L O D} \\
(\boldsymbol{\mu g} / \mathbf{m L})\end{array}$ \\
\hline Gallic acid & 1.1 & 270 & $0.2-10$ & $\mathrm{y}=112256 \mathrm{x}+2292.6$ & 0.9998 & 0.2 & 0.1 \\
Protocatechuic acid & 1.8 & 260 & $0.1-20$ & $\mathrm{y}=143215 \mathrm{x}-4179.8$ & 0.9999 & 0.1 & 0.05 \\
Chlorogenic acid & 2.1 & 327 & $0.125-6.25$ & $\mathrm{y}=110637+10485$ & 0.9992 & 0.125 & 0.0625 \\
Catechin & 2.6 & 280 & $0.6-90$ & $\mathrm{y}=28623 \mathrm{x}-12629$ & 0.9991 & 0.6 & 0.3 \\
Caffeic acid & 3.2 & 324 & $0.05-10$ & $\mathrm{y}=212078 \mathrm{x}-1682.3$ & 0.9997 & 0.05 & 0.025 \\
Epicatechin & 3.5 & 280 & $0.5-25$ & $\mathrm{y}=29894 \mathrm{x}-1630.5$ & 0.9998 & 0.5 & 0.125 \\
$p$-coumaric acid & 4.5 & 310 & $0.05-2.5$ & $\mathrm{y}=260742 \mathrm{x}+5928.8$ & 0.9991 & 0.05 & 0.025 \\
Ferulic acid & 5.1 & 323 & $0.075-3.75$ & $\mathrm{y}=224909 \mathrm{x}+5856.4$ & 0.9992 & 0.075 & 0.0375 \\
Fisetin & 7.5 & 360 & $0.2-2.5$ & $\mathrm{y}=124764 \mathrm{x}-12706$ & 0.9991 & 0.2 & 0.1 \\
\hline
\end{tabular}

Calibration curves were obtained for each of the studied compounds. The areas of the peaks were measured at the wavelength $(\lambda)$ characteristic of each phenolic compound in the extract. The determination coefficients were obtained according to the ICH guidelines $[23,24]$ and all values were higher than 
0.999, thus it was evidenced that the method was linear for all PCs in the working ranges used [25]. The concentration of each phenolic compound present in the extract was determined (Table 3).

Table 3. The concentration of the 9 PCs in the persimmon extract.

\begin{tabular}{cc}
\hline PC & Concentration $\mathbf{( m g / 1 0 0 ~} \mathbf{g}$ FW) \\
\hline Gallic acid & $2.794 \pm 0.263$ \\
Protocatechuic acid & $0.005 \pm 0.00$ \\
Chlorogenic acid & $0.171 \pm 0.016$ \\
Catechin & $0.071 \pm 0.00$ \\
Caffeic acid & $0.001 \pm 0.00$ \\
Epicatechin & $0.401 \pm 0.045$ \\
p-coumaric acid & $0.097 \pm 0.004$ \\
Ferulic acid & $0.027 \pm 0.002$ \\
Fisetin & $0.016 \pm 0.00$ \\
\hline
\end{tabular}

In this study, the gallic acid was the most abundant phenolic compound in the extract. The observed value was similar to the one reported by Pu et al. (2013) which found a concentration of $2.789 \mathrm{mg} / 100 \mathrm{~g}$ fresh weight (FW) in the variety D. kaki var. silvestris M [34]. However, Veberic and colleagues reported $2.43 \pm 0.215 \mathrm{mg} / 100 \mathrm{~g}$ FW [35]. The levels of the three hydroxycinnamic acids (chlorogenic acid, caffeic acid and ferulic acid) were below $0.1 \mathrm{mg} / 100 \mathrm{~g} \mathrm{FW}$, except for the chlorogenic acid content, as described by $\mathrm{Pu}$ et al. [34]. The chlorogenic acid concentration in this study was $0.171 \mathrm{mg} / 100 \mathrm{~g}$ FW D. kaki extract. It is possible to find published results of $0.274 \mathrm{mg} / 100 \mathrm{~g}$ FW in the variety of $D$. kaki var. silvestris $\mathrm{M}$ and $0.145 \mathrm{mg} / 100 \mathrm{~g} \mathrm{FW}$ in the variety of $D . k a k i \mathrm{cv}$. Xingyangshuishi [34]. The same authors did not find $p$-coumaric acid in 5 of the 6 genotypes analysed. The only genotype where $p$-coumaric acid was detected was in D. kaki var. silvestris $\mathrm{M}$, with a value of $0.048 \pm 0.004 \mathrm{mg} / 100 \mathrm{~g}$ FW [34], approximately twice less the concentration found in this study $0.097 \pm 0.004 \mathrm{mg} / 100 \mathrm{~g} \mathrm{FW}$.

Comparing with hydroxycinnamic acids [34,35], the amount of hydroxybenzoic acids was higher in the tested extract but the (+)-catechin and (-)-epicatechin contents were lower than previous values reported [36,37]. The same was observed with flavone fisetin [38]. However, it should be taken into consideration that the different stages of maturation and the different cultivar which might lead to a wide variability [6].

\subsection{Physical Characterization of Phytosomes}

The characterization parameters of the phytosomal formulation by dynamic laser scattering (DLS) technique after 0,3 and 6 months of storage are described in Table 4.

Table 4. The characterization of the phytosomes.

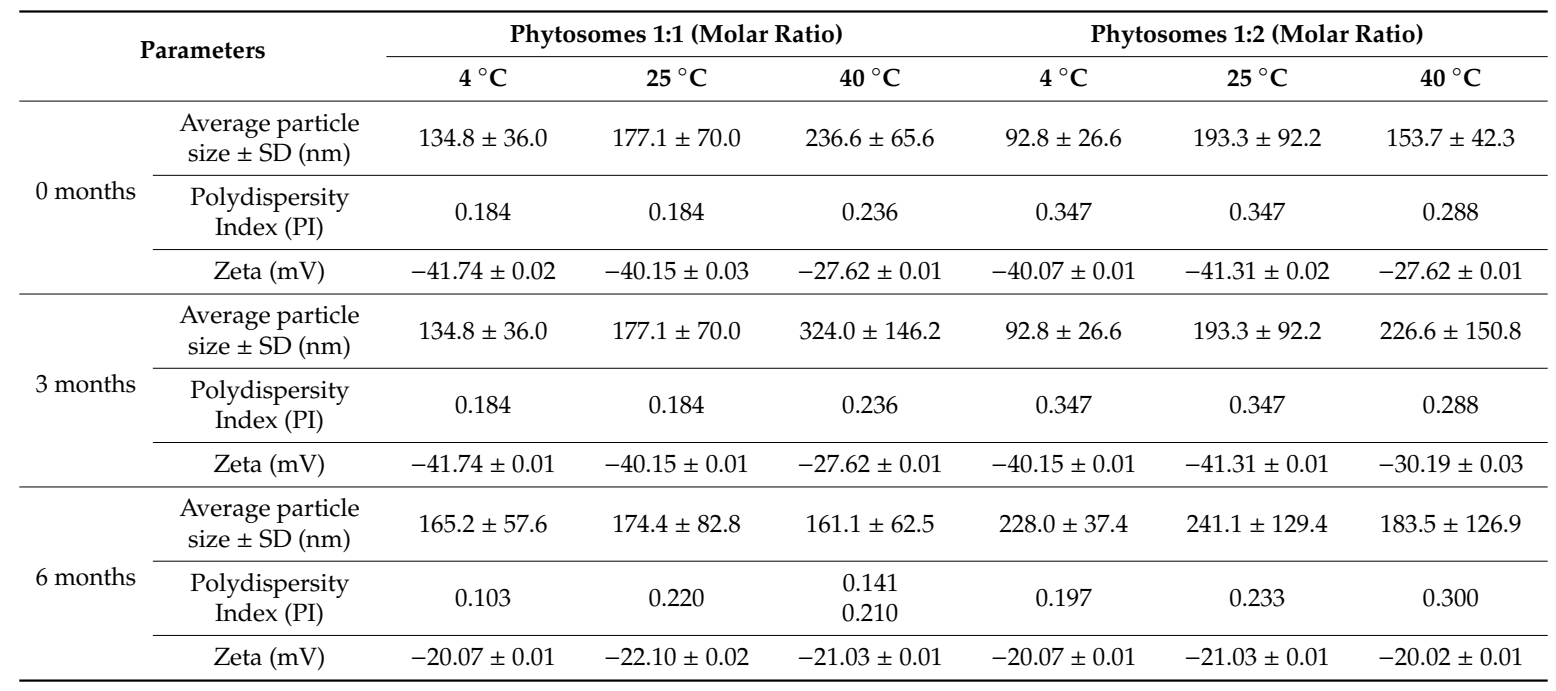


The size was similar regardless of the molar ratio with a size less than $300 \mathrm{~nm}$ (Figure 1). Phytosomes were monodispersed $(\mathrm{PI}<0.3)$ regardless of the storage temperature for the 1:1 formulation, excluding the $1: 2$ formulation at $25^{\circ}$ and $4^{\circ} \mathrm{C}$ during the first 3 months (Figure 2). The high lipid composition in the formulation (1:2) increased the tendency for the formation of agglomerates (PI $=0.347$, for 1:2 formulation at $25^{\circ}$ and $4{ }^{\circ} \mathrm{C}$ ), according to a study by Surini and colleagues [39].

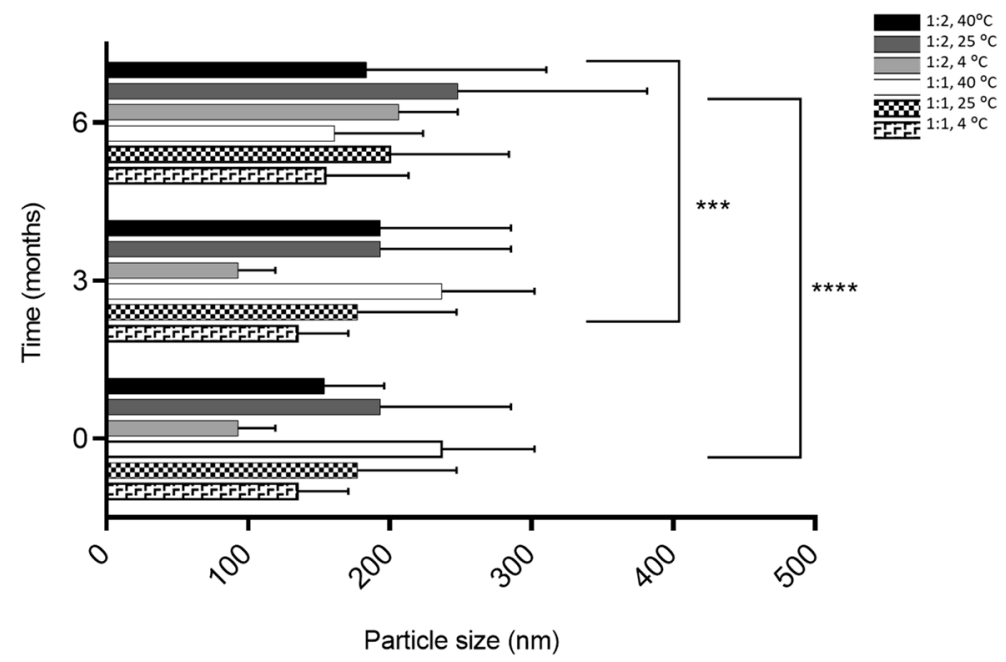

Figure 1. The influence of storage conditions of $\mathrm{T}$ and $\mathrm{RH}$ in phytosomal formulation size. ${ }^{* * *} p<$ $0.0001-0$ months vs. 6 months, ${ }^{* * *} p<0.05-3$ months vs. 6 months.

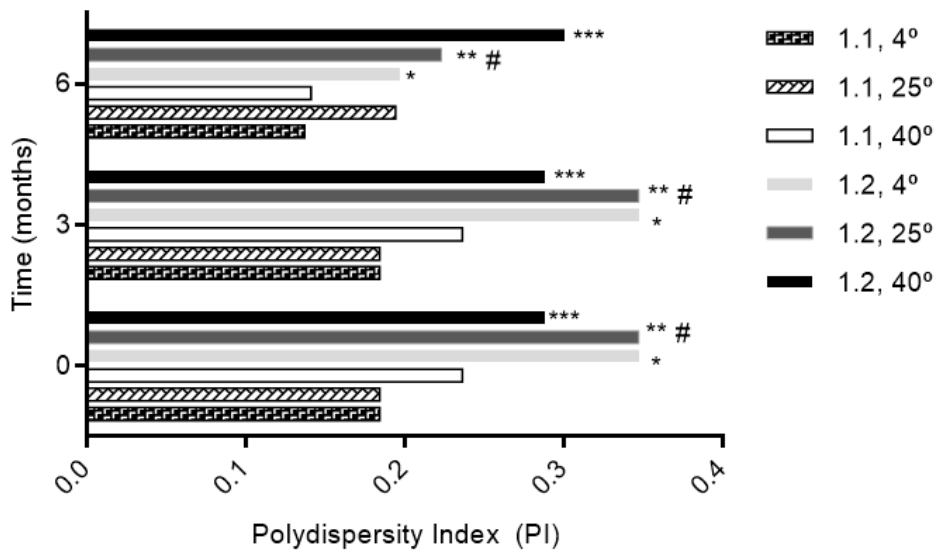

Figure 2. The influence of storage conditions of $\mathrm{T}$ and $\mathrm{RH}$ in PI of phytosomal formulation. ${ }^{*} p<0.05$ vs. $1: 1,4{ }^{\circ} \mathrm{C} ;{ }^{* *} p<0.05$ vs. $1: 1,4{ }^{\circ} \mathrm{C} ;{ }^{* * *} p<0.05$ vs. $1: 1,4{ }^{\circ} \mathrm{C} ; \# p<0.05$ vs. $1: 1,25^{\circ} \mathrm{C}$.

The general values of the zeta potential of these phytosomes were negative (Table 4 ). The zeta potential was between -41.74 and $-27.62 \mathrm{mV}$. The negative charge produced from the ethanol used in phytosome preparation may prevent the aggregation due to electrostatic repulsion and resistance forces [39]. The Surface charge expressed as zeta potential is an important physicochemical parameter that influences the stability of nanosuspensions which may also influence biodistribution, pharmacokinetics, and cellular affinity and drug internalization [40]. When compared to a positive one, the literature stated that negative zeta potential has been generally associated to higher biocompatibility $[41,42]$.

\subsection{Determination of Encapsulation Efficiency (EE)}

\subsubsection{EE Assessed by High-Performance Liquid Chromatography (HPLC) Analysis}

The chromatographic profile at $280 \mathrm{~nm}$ of the extract in the formulation is presented in Figure 3. 


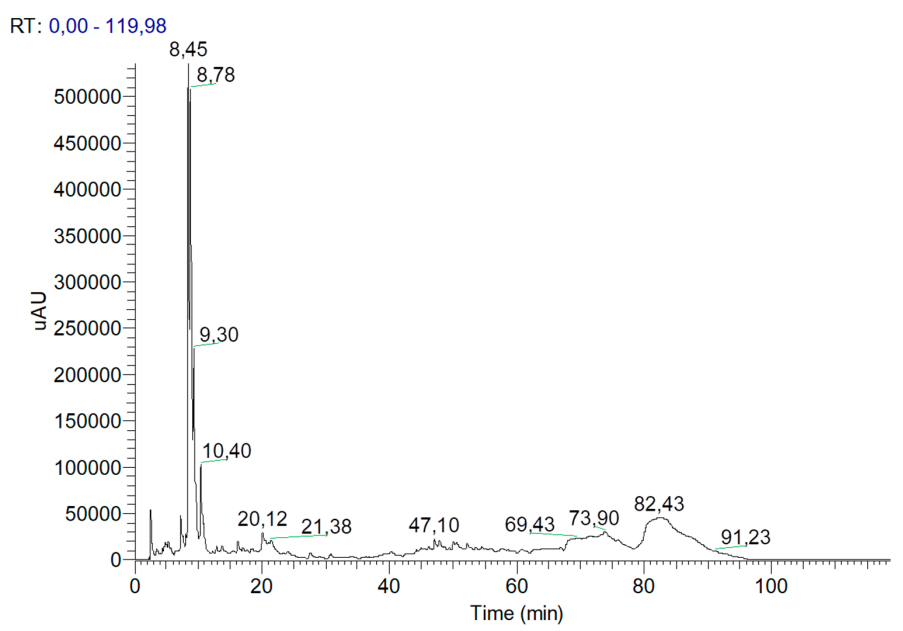

Figure 3. The chromatographic profile at $280 \mathrm{~nm}$ of the extract present in the formulation analysed by HPLC.

The most abundant compounds identified at this wavelength were gallic acid and catechin. At $360 \mathrm{~nm}$, the chromatographic profile showed that compounds like kaempferol and quercetin could be present in glycosylated forms. These results are in accordance with the literature [43-45].

Considering the total peak area at $280 \mathrm{~nm}$, it was concluded that the phytosomes were able to encapsulate $97.4 \%$ of the total phenolic content in the extract, encapsulating $99.3 \%$ of gallic acid present in the extract.

These results showed a high capability of encapsulation of the phytosomes for the extract.

\subsubsection{EE Assessed by Spectrophotometric Analysis}

The EE of the extract by phytosomes was further verified by Folin-Ciocalteau spectrophotometric methodology (Table 1). The concentration of total phenolics was $1112 \pm 34.6 \mathrm{mg} \mathrm{GAE} / \mathrm{L}$, and in the supernatant was $70.9 \pm 4.9 \mathrm{mg}$ GAE/L. Based on this methodology, the value of $\mathrm{EE}$ was $93.6 \%$, again more than $90 \%$. This value confirmed the high EE already determined.

The differences found between the determination of total phenolic compounds by spectrophotometric Folin-Ciocalteau method and HPLC, may be due to the fact that the Folin-Ciocalteau technique is not specific, also reacting with non-phenolic compounds [46-48] as sugars. As PCs are the most abundant antioxidants in most plants, this method is still the most used for the determination of total phenolic content [48].

\subsection{Determination of Antioxidant Activity (DPPH)}

These results, presented in Figure 4, demonstrated that these phytosomes maintained the behaviour of the extract, amplifying its antioxidant potential over time. In contrast to the free extract, extract-loaded phytosomes had higher antioxidant activity over 6 months. Specifically, at $40^{\circ} \mathrm{C}$, the decay of the antioxidant activity demonstrated by the 1:1 and 1:2 loaded phytosomes were respectively, four and six times lower than that demonstrated by the free extract under the same conditions. The quercetin standard had a decay of $51.8 \%$, approximately nine times higher than that of the free extract. When compared to loaded phytosomes, the quercetin standard declined 38 times more than the 1:1 formulation and 57 times more than the 1:2 formulation.

At $25{ }^{\circ} \mathrm{C}$, the decay of antioxidant activity of the extract and the phytosomes followed the same tendency, approximately between $10 \%$ and $15 \%$. On the other hand, the decay of antioxidant activity for the quercetin standard was $43.73 \%$, which is four times higher than that observed in the free extract, three times more than the loaded phytosomes with the highest decay $(1: 1)$, and approximately four times higher than 1:2 phytosomes under the same storage conditions. At $4{ }^{\circ} \mathrm{C}$, the quercetin standard 
exhibited a decay of antioxidant activity of $50.36 \%$. The free extract under the same conditions had a decay of this activity of $29.44 \%$ and the phytosomes between approximately $10 \%$ and $16 \%$.

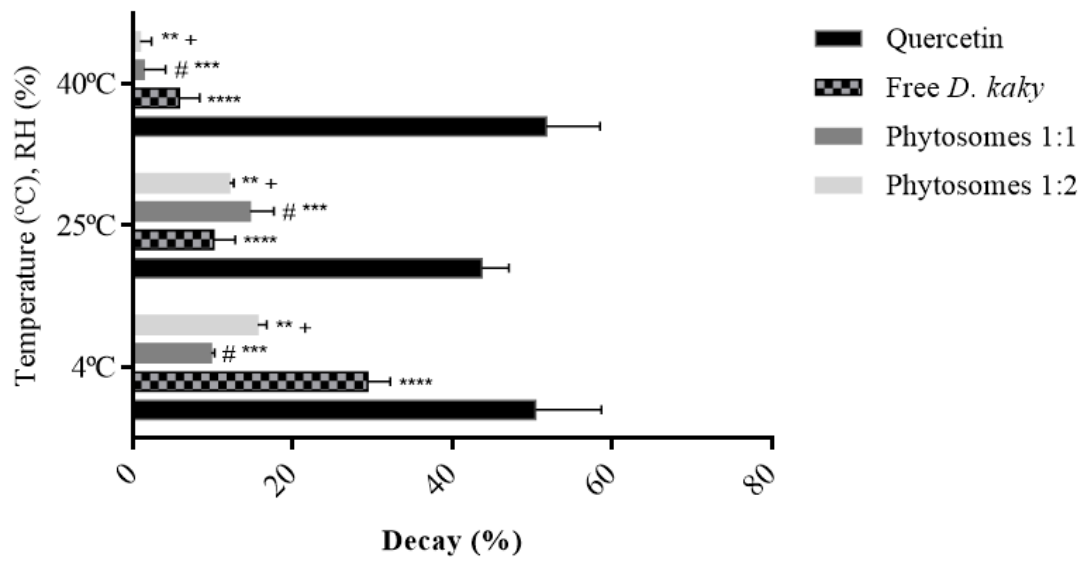

Figure 4. The percentage of decay of antioxidant activity of the free extract, phytosomes (molar ratio $1: 2$ and 1:1) and quercetin, in the conditions of temperature and humidity established (\%DPPHt $\left.-\% \mathrm{DPPHt}_{6}\right){ }^{* * * *} p<0.0001$ vs. quercetin, $\# p<0.0001$ vs. quercetin, ${ }^{* *} p<0.0001$ vs. quercetin, ${ }^{* * *} p<$ 0.0001 vs. free extract, $+p<0.0001$ vs. free extract.

Overall, it was found that phytosomes have a smaller loss of activity over the course of 6 months, particularly at $40{ }^{\circ} \mathrm{C}$, suggesting that these carriers maintained the behaviour of the extract and amplifyied its antioxidant activity over the study time in the storage conditions of temperature $(\mathrm{T})$ and relative humidity $(\mathrm{RH})$.

This encapsulation process is still a very useful process utilized in the incorporation of active ingredients aiming, among other objectives, to obtain a modified release of pharmaceutical compounds or protect them from harsh atmospheric agents (moisture, light, heat and/or oxidation). One similar example was also observed with extracts obtained from Plectranthus [27]. After encapsulation, the major compounds like chlorogenic acid (CA) and rosmarinic acid (RA) were encapsulated in calcium alginate beads and they were stable over time and against UV in contrast to free extracts (or non-encapsulated).

\subsection{Evaluation of In Vivo Experiment}

\subsubsection{Changes in Weight and Mortality}

As observed in Figure 5, the oral administration of free D. kaki extract or loaded phytosomes did not influence the body weight during the 15-day period. No difference in other clinical signs was observed between the test group dosed with extract-loaded phytosomes and the free extract group. There was no mortality in either group.

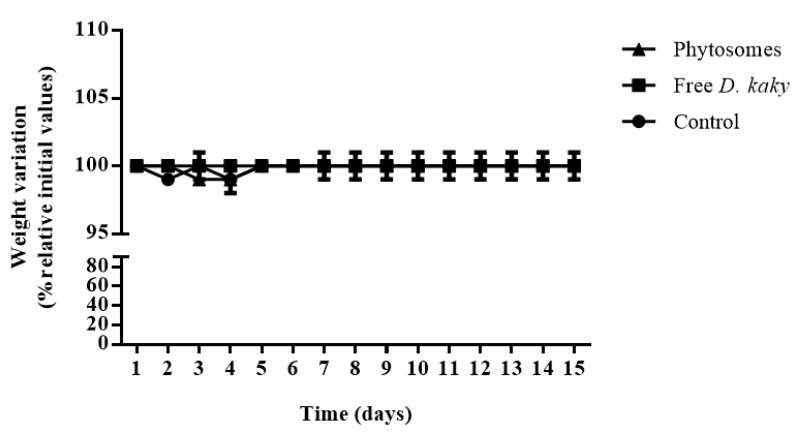

Figure 5. The variation in weight of rats during 15 days of oral administration of extract-loaded phytosomes (full triangles); free extract (full squares) and control (full circles) consisting of normal rats dosed with water. The data has been expressed by the means \pm SD. 


\subsubsection{Evaluation of Changes in Organs Function}

During the protocol, no changes were observed in this parameter. Normal rats showed an average value of glycaemia during protocol time around $156 \pm 5 \mathrm{mg} / \mathrm{dl}$. The group of free extract dosed had $158 \pm 15 \mathrm{mg} / \mathrm{dL}$ and phytosomes dosed group exhibited $154 \pm 22 \mathrm{mg} / \mathrm{dL}$. All values corresponded to normal glycaemia [18].

The urine analysis is presented in Table 5 . The values of the test group were similar to the control group except one case more of proteinuria, and one single case of ketonic bodies and bilirubin. In group dosed with free extract, animals presented more proteinuria and leucocytes. Glycosuria was not observed, and urine $\mathrm{pH}$ and density were similar for all groups.

Table 5. Urine analysis.

\begin{tabular}{|c|c|c|c|c|c|c|c|c|c|c|}
\hline Group & $\begin{array}{l}\text { Ketonic } \\
\text { bodies }\end{array}$ & $\begin{array}{l}\text { Glucose } \\
(\mathrm{mg} / \mathrm{dL})\end{array}$ & Proteinuria & Density & $\mathrm{pH}$ & Nitrites & Blood & Bilirubin & Uribilinogen & Leucocytes \\
\hline Control & - & - & $\begin{array}{l}1 \text { positive } \\
\text { case }\end{array}$ & $1.00-1.02$ & $5.0-7.5$ & - & - & - & $\mathrm{N}$ & $\begin{array}{l}1 \text { positive } \\
\text { case }\end{array}$ \\
\hline Phytosomes & $\begin{array}{l}1 \text { positive } \\
\text { case }\end{array}$ & - & $\begin{array}{l}2 \text { positive } \\
\text { case }\end{array}$ & $1.01-1.03$ & $6.0-7.5$ & - & - & $\begin{array}{l}1 \text { positive } \\
\text { case }\end{array}$ & $\mathrm{N}-4$ & $\begin{array}{l}1 \text { positive } \\
\text { case }\end{array}$ \\
\hline Free extract & - & - & $\begin{array}{l}4 \text { positive } \\
\text { cases }\end{array}$ & $1.01-1.03$ & $5.0-8.0$ & - & - & - & $\mathrm{N}-4$ & $\begin{array}{l}2 \text { positive } \\
\text { cases }\end{array}$ \\
\hline
\end{tabular}

- indicates result is not detected; $\mathrm{N}$, within normal range.

The haematological parameters are summarized in Table 6. Animals from the test group showed similarity of haematological parameters with the control group. The observed values were similar as the reference for healthy Wistar rats [49-51].

Table 6. The haematological parameters after 15 days of oral administration. The data has been expressed by the means $\pm \mathrm{SD}$.

\begin{tabular}{cccc}
\hline $\begin{array}{c}\text { Haematological } \\
\text { Parameters }\end{array}$ & Negative Control & Free Extract & $\begin{array}{c}\text { Extract-Loaded } \\
\text { Phytosomes }\end{array}$ \\
\hline $\mathrm{RBC}\left(\times 10^{12} / \mathrm{L}\right)$ & $8.1 \pm 0.2$ & $7.8 \pm 0.5$ & $8.0 \pm 0.4$ \\
\hline $\mathrm{Hb}(\mathrm{g} / \mathrm{dL})$ & $15.4 \pm 0.7$ & $14.7 \pm 0.7$ & $15.0 \pm 0.5$ \\
\hline Haematocrit $(\%)$ & $55.8 \pm 1.2$ & $53.1 \pm 3.7$ & $54.2 \pm 3.0$ \\
\hline WBC $\left(10^{9} / \mathrm{L}\right)$ & $3.3 \pm 0.0$ & $4.0 \pm 0.6$ & $5.0 \pm 0.4$ \\
\hline $\mathrm{MO}(\%)$ & $0.4 \pm 0.1$ & $0.7 \pm 0.8$ & $1.6 \pm 1.2$ \\
\hline $\mathrm{NEU}(\%)$ & $21.3 \pm 2.1$ & $19.0 \pm 1.2$ & $19.2 \pm 4.4$ \\
\hline $\mathrm{EO}(\%)$ & $1.7 \pm 0.2$ & $1.7 \pm 1.8$ & $1.6 \pm 0.90$ \\
\hline $\mathrm{BAS}(\%)$ & $0.0 \pm 0.0$ & $0.3 \pm 0.2$ & $77.4 \pm 6.3$ \\
\hline $\mathrm{LYM}(\%)$ & $76.7 \pm 2.5$ & $78.3 \pm 3.6$ & $705.8 \pm 123.3 * * * *$ \\
\hline Platelets $\left(10^{9} / \mathrm{L}\right)$ & $541.0 \pm 9.9$ & $443.6 \pm 112.3 * * * *$ & $67.9 \pm 0.8$ \\
\hline $\mathrm{MCV}(\mathrm{fL})$ & $68.7 \pm 0.1$ & $67.70 \pm 0.8$ & $18.8 \pm 0.5$ \\
\hline $\mathrm{MCH}(\mathrm{pg})$ & $19.0 \pm 0.5$ & $18.8 \pm 0.4$ & $27.7 \pm 0.8$ \\
\hline MCHC $(\mathrm{g} / \mathrm{dL})$ & $27.6 \pm 0.7$ & $27.8 \pm 0.8$ &
\end{tabular}

Other parameters are summarized in Table 7. Some biochemical parameters of the test group were similar to control values such as creatinine, total proteins, low density lipoprotein (LDL) and high density lipoprotein (HDL). 
Table 7. The biochemical parameters after 15 days of oral administration. The data has been expressed as the means $\pm \mathrm{SD}$.

\begin{tabular}{cccc}
\hline Biochemical Parameters & Control & Free Extract & Phytosomes \\
\hline UR $(\mathrm{mg} / \mathrm{dL})$ & $37.3 \pm 2.08$ & $35.8 \pm 1.64$ & $30.4 \pm 1.95^{*}$ \\
\hline CR $(\mathrm{mg} / \mathrm{dL})$ & $0.48 \pm 0.03$ & $0.50 \pm 0.01$ & $0.46 \pm 0.018$ \\
\hline ALT $(\mathrm{U} / \mathrm{L})$ & $42 \pm 2.65$ & $32.0 \pm 2.12^{* * *}$ & $24.8 \pm 2.39^{* * *}$ \\
\hline AST $(\mathrm{U} / \mathrm{L})$ & $194.67 \pm 5.86$ & $86.4 \pm 5.68^{* * *}$ & $107.4 \pm 5.41^{* * *}$ \\
\hline ALP $(\mathrm{U} / \mathrm{L})$ & $69 \pm 3.61$ & $90.2 \pm 3.11^{* * *}$ & $63.8 \pm 10.13^{*}$ \\
\hline T-PROT $(\mathrm{g} / \mathrm{dL})$ & $7.3 \pm 0.02$ & $7.32 \pm 0.03$ & $7.33 \pm 0.03$ \\
\hline CHOL $(\mathrm{mg} / \mathrm{dL})$ & $52.67 \pm 2.52$ & $57.2 \pm 1.48^{*}$ & $57.4 \pm 1.52^{*}$ \\
\hline TRIG $(\mathrm{mg} / \mathrm{dL})$ & $255.67 \pm 4.04$ & $273.0 \pm 3.4687^{* * *}$ & $287.6 \pm 2.77^{* * *}$ \\
\hline LDL $(\mathrm{mg} / \mathrm{dL})$ & $2.00 \pm 0.00$ & $1.4 \pm 0.55$ & $2.2 \pm 0.45$ \\
\hline HDL $(\mathrm{mg} / \mathrm{dL})$ & $43.67 \pm 1.53$ & $46.6 \pm 1.14$ & $42.6 \pm 1.14$ \\
\hline
\end{tabular}

* Statistically different from control with $p<0.05$. ${ }^{* *}$ Statistically different from control with $p<0.0001$.

In this study, the ranges of total serum protein were $7.3 \pm 0.02 \sim 7.33 \pm 0.03 \mathrm{~g} / \mathrm{dL}$. This concentration was within the reference range of $6.3 \sim 8.6 \mathrm{~g} / \mathrm{dL}$ for serum total protein concentration in Wistar rats [52].

The urea was slightly reduced in tested groups. According to referenced values [49], the renal function was accessed with the urea, creatinine parameters, and the oral administration of free extract, and phytosomes to the test groups did not change the renal function of these healthy rats.

The ALT level was reduced in both test groups when compared to the control group, and in the phytosome group, this reduction was greater than in the free extract. The reference values for ALT are generally between 17 and $50 \mathrm{U} / \mathrm{L}[50,51]$. In the case of AST, the values were lower in the test groups. The AST was found to be more reduced in the group of rats administered with free extract than in those administered with encapsulated extract, but all values were within the referenced range [49]. Concerning serum ALP concentration, it was lower in the phytosomes group than in the other groups, but closer to the control group. In the free extract group, there was even an increase in relation to the control group. These biomarkers of liver function indicated that this function has not been altered in relation to normal function. However, there was a decrease in the expression of all of them.

Triglycerides and cholesterol were statistically different from the control. The free extract somehow reduced the LDL expression and increased the HDL expression. Gorinstein and colleagues already described the improvement of biochemical analysis during a 4 week diet supplemented with dry persimmon and with phenol-free dry persimmon [53,54]. In the systematic review and meta-analysis of randomized clinical trials evaluating the relationship between green tea catechin (GTC) and serum lipid levels including LDL, HDL, and triglycerides, it concluded that the consumption of GTCs was associated with a statistically significant reduction in levels of total and LDL cholesterol. However, there was no significant effect on HDL or triglyceride levels [55], in addition to the positive correlation of catechin with the free radical sequestration capacity, demonstrated in previous studies [56].

\section{Discussion}

Persimmon is a fruit that is known by its composition in nutritious and bioactive components, with a great potential for its use within the cosmetic and pharmaceutical industries [9,56-62]. This study and previous ones described persimmons as a fruit rich in PCs, such as gallic acid [63] and flavonoids [64].

The dosages of the total phenolic content in the persimmon fruit described in the literature varied widely. Denev and colleges determined 916.8mg GAE/100g FW [65]. In the studies of Veberic et al. with 11 different cultivars, values ranged from 12.7 to $29.5 \mathrm{mg}$ GAE/100g FW [35]. The wide variability observed in these assays can be explained on the basis of the edaphoclimatic conditions, different opossum cultivars analysed, and stage of maturation, even when the fruit is more adequate for 
consumption. In addition, the different extraction methods applied and the analytical method protocols may have influenced the results [6]. Gallic acid was the most abundant PC in the extract and is well known in the traditional Chinese medicine, for its antioxidant properties, protecting from oxidative stress damages, increasing survival $[34,66]$. The phytosomes prepared in this work were able to encapsulate $99.3 \%$ of gallic acid present in the extract and $97.4 \%$ of total phenolic compounds.

This type of carrier system has been used when poor oral and/or erratic oral bioavailability of the polyphenols $[67,68]$ occurred. In general, the encapsulation process can improve the rate of absorption, the extent of solubilisation in aqueous intestinal fluids and also to improve their ability to cross biomembranes $[68,69]$. The activity of these complexes has been widely described in several fields of application like cardiovascular [70], anti-inflammatory [71], hepatoprotective [72,73], anticancer [74], and even as cosmetics (anti-skin aging) [75].

The results showed that monodisperse phytosomes were successfully prepared with size ranges of less than $300 \mathrm{~nm}$ for both formulations over time at all $\mathrm{T}$ and RH conditions tested, given that this small particle size is important for oral absorption [76]. In this study, the size was managed regardless of the molar ratio, over 6 months of storage at different $\mathrm{T}$ and $\mathrm{RH}$, which predicted the stability of the formulation. The size is an important factor for oral absorption and formulation stability in order to achieve a significant improvement in the bioavailability of persimmon PC. Previous studies have shown that a reduction in the size of the drug delivery systems improved their intestinal absorption $[77,78]$. It should also be noted that it has been described that size lower than $277 \mathrm{~nm}$ increased the emulsion stability of vitamin E-loaded phytosomes [79]. Moreover, some findings in lycopene nanoemulsions also showed that droplet sizes between 100 and $200 \mathrm{~nm}$ exhibited high anti-radical efficiency and antioxidant activities [80,81].

The narrow size distribution of carriers guarantees the uniformity and predictability of delivery of bioactive compounds [82]. The value of PI, indicative of the degree of heterogeneity regarding sample size, is another parameter possible to assess. There is an inherent polydispersity within any given batch of submicron particles, which needs to be controlled for predictable interaction with cells, otherwise different batches of the same material might display different results in cell studies [83]. The PI showed that monodisperse populations of phytosomes were obtained, especially for molar ratio of $1: 1$, at all temperatures. The higher ratio led to some agglomeration. A small value of PI $(<0.3)$ indicated a homogenous population, while a larger PI $(>0.3)$ meant a high heterogeneity $[84,85]$.

Li et al. (2011) optimized the formulation of the extract containing self-emulsifying delivery systems, where droplet dispersion sizes ranged between $100-250 \mathrm{~nm}$, having $44.48 \mathrm{mg}$ total flavonoids/g persimmon leaf extract. The oral bioavailability of quercetin and kaempferol in vivo in beagle dogs was significantly enhanced by smaller nanoparticles, compared with commercial tablets. According to the in vitro-in vivo correlation study, the oral bioavailability enhancement was due to the increased drug concentration within the GI tract and its absorption area [86].

The phytosomes prepared in this work exhibited negative zeta potential, between -20 and $-40 \mathrm{mV}$. In general, high positive or high negative zeta potential values may cause strong repulsive forces, whereas particles with similar electric charges may cause repulsion between them, preventing aggregation of the particles and easy re-dispersion $[87,88]$. In a scenario with combined electrostatic and steric stabilization, it is desirable that a minimum zeta potential of $\pm 20 \mathrm{mV}$ [42], whereas a high zeta potential (positive or negative) should maintain a physically stable system [89]. However, it should be noted that negatively charged particles are cleared away more slowly from the blood when compared to positively charged particles, remaining within the bloodstream for longer periods of time [90]. This suggests the potential of this formulation was also related to the EE calculated, which was close to $100 \%$.

In studies with nanoparticles, Shyam et al. [91] developed gallic acid phospholipids complex in different ratios to improve the lipophilic properties of gallic acid and to overcome its poor absorption because of less lipophilicity. They reported that gallic phospholipids complex was an effective scavenger of DPPH radicals with strong antioxidant activity [91]. Maiti et al. [92] reported that phytosomes 
of curcumin (flavonoid from turmeric, Curcuma longa) and naringenin (flavonoid from grape fruit, Vitis vinifera) showed higher antioxidant activity than pure curcumin in all dose levels tested [92], which is in accordance with present results, where pure quercetin alone showed an antioxidant activity lower than the free extract and phytosomes tested. Both tested formulations were very stable in terms of antioxidant activity. In 6 months of storage, at different conditions of T/RH, they exhibited losses of antioxidant activity of less than $20 \%$, which did not occur for the free extract, or even for instance, for the positive control (quercetin).

Naik et al. [93] prepared grape seed phytosomes which were composed by oligomeric polyphenols (grape proanthocyanidins or procyanidins from grape seed extract, Vitis vinifera) complexed with phospholipids. They indicated that total antioxidant capacity and stimulation of physiological antioxidant defences increased through a network of mechanisms that extended beyond their great antioxidant potency, offering a marked protection for the cardiovascular system and other organs [93]. In the present study, it was observed that repeated-dose oral administration of phytosomes and extract in healthy rats did not change organ functions or body weight after a 15-day period. There were no mortalities or any deviation from normality in regards to clinical signs after the oral administration of the extract-loaded phytosomes or the free extract. All haematological, biochemical and urine parameters were within the reference values, suggesting the in vivo safety of this novel oral dosage form and the potential therapeutic use of this dosage form in order to deliver these active components of the fruit. The potential applications are varied, and given the antioxidant potential and already demonstrated anti-inflammatory effects [9], clinical situations associated to chronic inflammation might benefit from administration of the extract in phytosomes. Future studies should aim at characterising the pharmacokinetics of these phytosomes, with special interest in their bioacessibility and bioavailability.

\section{Conclusions}

This study showed, for the first time, phytosomes with aqueous persimmon extract for potential application as a food supplement. Monodisperse phytosomes were successfully prepared with size ranges of less than $300 \mathrm{~nm}$. In contrast to the free extract, the extract-loaded phytosomes had higher antioxidant activity over 6 months and under accelerated storage conditions. These phytosomes were also able to encapsulate $97.4 \%$ of total phenolics, protecting them from the harsh environment like heat and humidity. From the PCs quantified in the persimmon extract, gallic acid was present in the highest concentration; the epicatechin was the second most abundant compound; followed by chlorogenic, $p$-coumaric, catechin, and ferulic acid; and finally, fisetin, protocatechuic acid, and caffeic acid. Additionally, the results suggested that the polyphenolic extracts of persimmon in phytosomal formulation were an interesting dosage form for nutraceutical purposes. To the best knowledge of the authors, there is no record of any formula with persimmon fruit extract involving phytosomes. With this study, the authors could suggest that these systems may be considered as promising candidates for the future delivery of bioactive agents of the persimmon fruit extracts. However, further integrated research is still needed to improve meticulousness, deepen the mechanisms of action, and its chronic use.

Author Contributions: Conceptualization, R.D., C.R., M.R.B. and M.E.F.; methodology, formal analysis, investigation and data curation, R.D., C.R., L.R., M.M.G., A.S.-S., M.G., R.P., J.R., B.S., M.R.B. and M.E.F.; writing-original draft preparation, R.D., C.R., L.R., M.M.G., A.S.-S., M.G., B.S. and M.E.F.; writing-review and editing, R.D., B.S., M.R.B. and M.E.F.; supervision, C.R., M.R.B., M.E.F.; funding acquisition, M.E.F.

Funding: This research was funded by Universidade de Lisboa PhD grant: REITORIA/BD/FF01/2015 and supported in part through Grant UID/DTP/04138/2019 from Fundação para a Ciência e a Tecnologia (FCT), Portugal.

Conflicts of Interest: The authors declare no conflict of interest. The funders had no role in the design of the study; in the collection, analyses, or interpretation of data; in the writing of the manuscript, or in the decision to publish the results. 


\section{References}

1. Newman, D.J.; Cragg, G.M. Natural products as sources of new drugs over the 30 years from 1981 to 2010. J. Nat. Prod. 2012, 75, 311-335. [CrossRef] [PubMed]

2. González-Vallinas, M.; González-Castejón, M.; Rodríguez-Casado, A.; Ramírez de Molina, A. Dietary phytochemicals in cancer prevention and therapy: A complementary approach with promising perspectives. Nutr. Rev. 2013, 71, 585-599. [CrossRef] [PubMed]

3. Zhao, D.Q.; Zhou, C.H.; Sheng, Y.L.; Liang, G.H.; Tao, J. Molecular cloning and expression of phytoene synthase, lycopene beta-cyclase, and beta-carotene hydroxylase genes in persimmon (Diospyros kaki L.) fruits. Plant Mol. Biol. Rep. 2011, 29, 345-351. [CrossRef]

4. Karaman, S.; Toker, O.S.; Yuksel, F.; Cam, M.; Kayacier, A.; Dogan, M. Physicochemical, bioactive, and sensory properties of persimmon-based ice cream: Technique for order preference by similarity to ideal solution to determine optimum concentration. J. Dairy Sci. 2014, 97, 97-110. [CrossRef] [PubMed]

5. Piretti, M.V. Polyphenol constituents of the diospyros kaki fruit. A review. Fitoterapia 1991, 62, 3-13.

6. Giordani, E.; Doumett, S.; Nin, S.; Del Bubba, M. Selected primary and secondary metabolites in fresh persimmon (Diospyros kaki thunb.): A review of analytical methods and current knowledge of fruit composition and health benefits. Food Res. Int. 2011, 44, 1752-1767. [CrossRef]

7. Xie, C.; Xie, Z.; Xu, X.; Yang, D. Persimmon (Diospyros Kaki L.) leaves: A review on traditional uses, phytochemistry and pharmacological properties. J. Ethnopharmacol. 2015, 163, 229-240. [CrossRef]

8. Khanal, P.; Oh, W.K.; Thuong, P.T.; Cho, S.D.; Choi, H.S. 24-hydroxyursolic acid from the leaves of the diospyros kaki (persimmon) induces apoptosis by activation of amp-activated protein kinase. Planta Med. 2010, 76, 689-693. [CrossRef]

9. Direito, R.; Lima, A.; Rocha, J.; Ferreira, R.B.; Mota, J.; Rebelo, P.; Fernandes, A.; Pinto, R.; Alves, P.; Bronze, R.; et al. Dyospiros kaki phenolics inhibit colitis and colon cancer cell proliferation, but not gelatinase activities. J. Nutr. Biochem. 2017, 46, 100-108. [CrossRef]

10. Crozier, A.; Jaganath, I.B.; Clifford, M.N. Dietary phenolics: Chemistry, bioavailability and effects on health. Nat. Prod. Rep. 2009, 26, 1001-1043. [CrossRef]

11. Ma, J.; Liu, X.-Y.; Noh, K.-H.; Kim, M.-J.; Song, Y.-S. Protective effects of persimmon leaf and fruit extracts against acute ethanol-induced hepatotoxicity. Prev. Nutr. Food Sci. 2007, 12, 202-208. [CrossRef]

12. Lipinski, C.A.; Lombardo, F.; Dominy, B.W.; Feeney, P.J. Experimental and computational approaches to estimate solubility and permeability in drug discovery and development settings1. Adv. Drug Deliv. Rev. 2001, 46, 3-26. [CrossRef]

13. Matias, D.; Rijo, P.; Pinto Reis, C. Phytosomes as biocompatible carriers of natural drugs. Curr. Med. Chem. 2017, 24, 568-589. [CrossRef] [PubMed]

14. Semalty, A.; Semalty, M.; Rawat, M.S.M.; Franceschi, F. Supramolecular phospholipids-polyphenolics interactions: The phytosome ${ }^{\circledR}$ strategy to improve the bioavailability of phytochemicals. Fitoterapia 2010, 81 , 306-314. [CrossRef] [PubMed]

15. Bernardes, C.E.; Garcia, C.; Pereira, F.; Mota, J.; Pereira, P.; Cebola, M.J.; Reis, C.P.; Correia, I.; Piedade, M.F.M.; Minas da Piedade, M.E.; et al. Extraction optimization and structural and thermal characterization of the antimicrobial abietane $7 \alpha$-acetoxy-6 $\beta$-hydroxyroyleanone. Mol. Pharm. 2018, 15, 1412-1419. [CrossRef] [PubMed]

16. Nicolai, M.; Pereira, P.; Vitor, R.F.; Reis, C.P.; Roberto, A.; Rijo, P. Antioxidant activity and rosmarinic acid content of ultrasound-assisted ethanolic extracts of medicinal plants. Measurement 2016, 89, 328-332. [CrossRef]

17. Pereira, F.; Baptista, R.; Ladeiras, D.; Madureira, A.M.; Teixeira, G.; Rosado, C.; Fernandes, A.S.; Ascensão, L.; Silva, C.O.; Reis, C.P. Production and characterization of nanoparticles containing methanol extracts of portuguese lavenders. Measurement 2015, 74, 170-177. [CrossRef]

18. Reis, C.P.; Figueiredo, I.V.; Carvalho, R.A.; Jones, J.; Nunes, P.; Soares, A.F.; Silva, C.F.; Ribeiro, A.J.; Veiga, F.J.; Damgé, C. Toxicological assessment of orally delivered nanoparticulate insulin. Nanotoxicology 2008, 2, 205-217. [CrossRef]

19. Abrantes, C.G.; Duarte, D.; Reis, C.P. An overview of pharmaceutical excipients: Safe or not safe? J. Pharm. Sci. 2016, 105, 2019-2026. [CrossRef] 
20. Wu, P.W.; Hwang, L.S. Determination of soluble persimmon tannin by high performance gel permeation chromatography. Food Res. Int. 2002, 35, 793-800. [CrossRef]

21. Jang, I.C.; Jo, E.K.; Bae, M.S.; Lee, H.J.; Jeon, G.I.; Park, E.; Yuk, H.G.; Ahn, G.H.; Lee, S.C. Antioxidant and antigenotoxic activities of different parts of persimmon (Diospyros kaki cv. Fuyu) fruit. J. Med. Plants Res. 2010, 4, 155-160.

22. Stamatakis, G.; Tsantila, N.; Samiotaki, M.; Panayotou, G.N.; Dimopoulos, A.C.; Halvadakis, C.P.; Demopoulos, C.A. Detection and isolation of antiatherogenic and antioxidant substances present in olive mill wastes by a novel filtration system. J. Agric. Food Chem. 2009, 57, 10554-10564. [CrossRef] [PubMed]

23. ICH (International Harmonisation Co). Guidance for Industry: Q2a Text on Validation of Analytical Procedures; Dept. of Health and Human Services, Food and Drug Administration, Center for Drug Evaluation and Research: Rockville, MD, USA, 1995.

24. ICH (International Harmonisation Co). Guidance for Industry: Q2b Validation of Analytical Procedures, Methodology; Dept. of Health and Human Services, Food and Drug Administration, Center for Drug Evaluation and Research: Rockville, MD, USA, 1996.

25. Oliveira, A.S.; Ribeiro-Santos, R.; Ramos, F.; Castilho, M.C.; Sanches-Silva, A. Uhplc-dad multi-method for determination of phenolics in aromatic plants. Food Anal. Method 2018, 11, 440-450. [CrossRef]

26. Matias, D.; Roque, L.; Simões, M.d.F.; Diaz-Lanza, A.; Rijo, P.; Reis, C.P. Plectranthus madagascariensis phytosomes: Formulation optimization. Biomed. Biopharm. Res. 2015, 12, 223-231. [CrossRef]

27. Rijo, P.; Matias, D.; Fernandes, A.S.; Simões, M.F.; Nicolai, M.; Reis, C.P. Antimicrobial plant extracts encapsulated into polymeric beads for potential application on the skin. Polymers 2014, 6, 479-490. [CrossRef]

28. Abd El-Fattah, A.I.; Fathy, M.M.; Ali, Z.Y.; El-Garawany, A.A.; Mohamed, E.K. Enhanced therapeutic benefit of quercetin-loaded phytosome nanoparticles in ovariectomized rats. Chem. Biol. Interact. 2017, 271, 30-38. [CrossRef] [PubMed]

29. Xu, X.; Fu, Y.; Hu, H.; Duan, Y.; Zhang, Z. Quantitative determination of insulin entrapment efficiency in triblock copolymeric nanoparticles by high-performance liquid chromatography. J. Pharm. Biomed. Anal. 2006, 41, 266-273. [CrossRef]

30. Fan, W.; Xia, D.; Zhu, Q.; Li, X.; He, S.; Zhu, C.; Guo, S.; Hovgaard, L.; Yang, M.; Gan, Y. Functional nanoparticles exploit the bile acid pathway to overcome multiple barriers of the intestinal epithelium for oral insulin delivery. Biomaterials 2018, 151, 13-23. [CrossRef]

31. Medicines, R.o. SADC Guideline for Stability Testing; Southern African Development Community: Gaborone, Botswana, 2004.

32. World Health Organization (WHO) Expert Committee on Specifications for Pharmaceutical Preparations; WHO Technical Report Series; Library and Information Networks for Knowledge: Geneva, Switzerland, 2009.

33. Sucupira, N.; Silva, A.; Pereira, G.; Costa, J. Methods for measuring antioxidant activity of fruits. UNOPAR Cient Ciênc Biol Saúde 2012, 14, 263-269.

34. Pu, F.; Ren, X.-L.; Zhang, X.-P. Phenolic compounds and antioxidant activity in fruits of six Diospyros kaki genotypes. Eur. Food Res. Technol. 2013, 237, 923-932. [CrossRef]

35. Veberic, R.; Jurhar, J.; Mikulic-Petkovsek, M.; Stampar, F.; Schmitzer, V. Comparative study of primary and secondary metabolites in 11 cultivars of persimmon fruit (Diospyros Kaki L.). Food Chem. 2010, 119, 477-483. [CrossRef]

36. Fu, L.; Xu, B.-T.; Xu, X.-R.; Gan, R.-Y.; Zhang, Y.; Xia, E.-Q.; Li, H.-B. Antioxidant capacities and total phenolic contents of 62 fruits. Food Chem. 2011, 129, 345-350. [CrossRef] [PubMed]

37. Gorinstein, S.; Martín-Belloso, O.; Park, Y.-S.; Haruenkit, R.; Lojek, A.; Cížz, M.; Caspi, A.; Libman, I.; Trakhtenberg, S. Comparison of some biochemical characteristics of different citrus fruits. Food Chem. 2001, 74, 309-315. [CrossRef]

38. Arai, Y.; Watanabe, S.; Kimira, M.; Shimoi, K.; Mochizuki, R.; Kinae, N. Dietary intakes of flavonols, flavones and isoflavones by japanese women and the inverse correlation between quercetin intake and plasma ldl cholesterol concentration. J. Nutr. 2000, 130, 2243-2250. [CrossRef] [PubMed]

39. Surini, S.; Mubarak, H.; Ramadon, D. Cosmetic serum containing grape (Vitis vinifera L.) seed extract phytosome: Formulation and in vitro penetration study. J. Young Pharm. 2018, 10, S51. [CrossRef]

40. Kraft, J.C.; Freeling, J.P.; Wang, Z.; Ho, R.J.Y. Emerging research and clinical development trends of liposome and lipid nanoparticle drug delivery systems. J. Pharm. Sci. 2014, 103, 29-52. [CrossRef] [PubMed] 
41. El Badawy, A.M.; Silva, R.G.; Morris, B.; Scheckel, K.G.; Suidan, M.T.; Tolaymat, T.M. Surface charge-dependent toxicity of silver nanoparticles. Environ. Sci. Technol. 2011, 45, 283-287. [CrossRef]

42. Honary, S.; Zahir, F. Effect of zeta potential on the properties of nano-drug delivery systems-a review (part 2). Trop. J. Pharm. Res. 2013, 12, 265-273.

43. Gu, H.F.; Li, C.M.; Xu, Y.J.; Hu, W.F.; Chen, M.H.; Wan, Q.H. Structural features and antioxidant activity of tannin from persimmon pulp. Food Res. Int. 2008, 41, 208-217. [CrossRef]

44. Jimenez-Sanchez, C.; Lozano-Sanchez, J.; Marti, N.; Saura, D.; Valero, M.; Segura-Carretero, A.; Fernandez-Gutierrez, A. Characterization of polyphenols, sugars, and other polar compounds in persimmon juices produced under different technologies and their assessment in terms of compositional variations. Food Chem. 2015, 182, 282-291. [CrossRef]

45. Engels, C.; Grater, D.; Esquivel, P.; Jimenez, V.M.; Ganzle, M.G.; Schieber, A. Characterization of phenolic compounds in jocote (Spondias Purpurea L.) peels by ultra-high-performance liquid chromatography/electrospray ionization mass spectrometry. Food Res. Int. 2012, 46, 557-562. [CrossRef]

46. De Oliveira, A.C.; Valentim, I.B.; Silva, C.A.; Bechara, E.J.H.; Barros, M.P.d.; Mano, C.M.; Goulart, M.O.F. Total phenolic content and free radical scavenging activities of methanolic extract powders of tropical fruit residues. Food Chem. 2009, 115, 469-475. [CrossRef]

47. Huang, D.; Ou, B.; Prior, R.L. The chemistry behind antioxidant capacity assays. J. Agric. Food Chem. 2005, 53, 1841-1856. [CrossRef] [PubMed]

48. Everette, J.D.; Bryant, Q.M.; Green, A.M.; Abbey, Y.A.; Wangila, G.W.; Walker, R.B. Thorough study of reactivity of various compound classes toward the folin-ciocalteu reagent. J. Agric. Food Chem. 2010, 58, 8139-8144. [CrossRef] [PubMed]

49. Branco, A.; Diniz, M.; Almeida, R.; Santos, H.; Oliveira, K.; Ramalho, J.; Dantas, J. Biochemical and hematological parameters of wistar rats and swiss mice in the professor thomas george animal laboratory. R Bras. Ci Saúde 2011, 15, 209-214. [CrossRef]

50. Demers, G.; Griffin, G.; De Vroey, G.; Haywood, J.R.; Zurlo, J.; Bédard, M. Harmonization of animal care and use guidance. Science 2006, 312, 700-701. [CrossRef] [PubMed]

51. Care, C.C.o.A. Guide to the Care and Use of Experimental Animals; Canadian Council on Animal Care: Ottawa, ON, Canada, 1993; Volume I.

52. Kim, H. The Korea Society of Food Science and Nutrition Hand Book of Experiments in Food Science and Nutrition; Hyoil Publishing Co: Seoul, Korea, 2000.

53. Gorinstein, S.; Kulasek, G.W.; Bartnikowska, E.; Leontowicz, M.; Zemser, M.; Morawiec, M.; Trakhtenberg, S. The effects of diets, supplemented with either whole persimmon or phenol-free persimmon, on rats fed cholesterol. Food Chem. 2000, 70, 303-308. [CrossRef]

54. Gorinstein, S.; Bartnikowska, E.; Kulasek, G.; Zemser, M.; Trakhtenberg, S. Dietary persimmon improves lipid metabolism in rats fed diets containing cholesterol. J. Nutr. 1998, 128, 2023-2027. [CrossRef] [PubMed]

55. Kim, A.; Chiu, A.; Barone, M.K.; Avino, D.; Wang, F.; Coleman, C.I.; Phung, O.J. Green tea catechins decrease total and low-density lipoprotein cholesterol: A systematic review and meta-analysis. J. Am. Diet. Assoc. 2011, 111, 1720-1729. [CrossRef]

56. Chen, X.N.; Fan, J.F.; Yue, X.; Wu, X.R.; Li, L.T. Radical scavenging activity and phenolic compounds in persimmon (Diospyros kaki L. Cv. Mopan). J. Food Sci. 2008, 73, C24-C28. [CrossRef]

57. Anunciato, T.P.; da Rocha Filho, P.A. Carotenoids and polyphenols in nutricosmetics, nutraceuticals, and cosmeceuticals. J. Cosmet. Dermatol. 2012, 11, 51-54. [CrossRef] [PubMed]

58. Tsang, M.; Jiao, D.; Chan, B.; Hon, K.-L.; Leung, P.; Lau, C.; Wong, E.; Cheng, L.; Chan, C.; Lam, C. Anti-inflammatory activities of pentaherbs formula, berberine, gallic acid and chlorogenic acid in atopic dermatitis-like skin inflammation. Molecules 2016, 21, 519. [CrossRef] [PubMed]

59. Kumar, K.J.; Vani, M.G.; Wang, S.Y.; Liao, J.W.; Hsu, L.S.; Yang, H.L.; Hseu, Y.C. In vitro and in vivo studies disclosed the depigmenting effects of gallic acid: A novel skin lightening agent for hyperpigmentary skin diseases. Biofactors 2013, 39, 259-270. [CrossRef] [PubMed]

60. Zhou, Z.D.; Huang, Y.; Liang, J.T.; Ou, M.L.; Chen, J.J.; Li, G.Y. Extraction, purification and anti-radiation activity of persimmon tannin from Diospyros kaki L.f. J. Environ. Radioact. 2016, 162, 182-188. [CrossRef] [PubMed]

61. Fushimi, S.; Myazawa, F.; Nakagawa, K.; Burdeos, G.C.; Miyazawa, T. Young persimmon ingestion suppresses lipid oxidation in rats. J. Nutr. Sci. Vitaminol. 2015, 61, 90-95. [CrossRef] [PubMed] 
62. Hamauzu, Y.; Suwannachot, J. Non-extractable polyphenols and in vitro bile acid-binding capacity of dried persimmon (Diospyros kaki) fruit. Food Chem. 2019, 293, 127-133. [CrossRef] [PubMed]

63. Gorinstein, S.; Zemser, M.; Weisz, M.; Halevy, S.; Deutsch, J.; Tilus, K.; Feintuch, D.; Guerra, N.; Fishman, M.; Bartnikowska, E. Fluorometric analysis of phenolics in persimmons. Biosci. Biotech. Biochem. 1994, 58, 1087-1092. [CrossRef]

64. Halsam, E.; Lilley, T.H. Natural astringency in foodstuffs-A molecular interpretation. Crit. Rev. Food Sci. Nutr. 1988, 27, 1-40.

65. Denev, P.; Yordanov, A. Total polyphenol, proanthocyanidin and flavonoid content, carbohydrate composition and antioxidant activity of persimmon (Diospyros kaki L.) fruit in relation to cultivar and maturity stage. Bulg. J. Agric. Sci. 2013, 19, 981-988.

66. Salcedo, C.L.; Frías, M.A.; Cutro, A.C.; Nazareno, M.A.; Disalvo, E.A. Antiradical activity of gallic acid included in lipid interphases. Biochim. Biophys. Acta (Bba) Biomembr. 2014, 1838, 2656-2661. [CrossRef]

67. Rasaie, S.; Ghanbarzadeh, S.; Mohammadi, M.; Hamishehkar, H. Nano phytosomes of quercetin: A promising formulation for fortification of food products with antioxidants. Pharm. Sci. 2014, 20, 96-101.

68. Belcaro, G.; Cesarone, M.R.; Dugall, M.; Pellegrini, L.; Ledda, A.; Grossi, M.G.; Togni, S.; Appendino, G. Efficacy and safety of meriva(r), a curcumin-phosphatidylcholine complex, during extended administration in osteoarthritis patients. Altern. Med. Rev. 2010, 15, 337-344. [PubMed]

69. Li, H.; Zhao, X.; Ma, Y.; Zhai, G.; Li, L.; Lou, H. Enhancement of gastrointestinal absorption of quercetin by solid lipid nanoparticles. J. Control. Release 2009, 133, 238-244. [CrossRef] [PubMed]

70. Panda, V.S.; Naik, S.R. Evaluation of cardioprotective activity of Ginkgo biloba and Ocimum sanctum in rodents. Altern. Med. Rev. 2009, 14, 161-171. [PubMed]

71. Bombardelli, E.; Spelta, M. Phospholipid-polyphenol complexes: A new concept in skin care ingredients. Cosmet. Toilet. 1991, 106, 69-76.

72. Loguercio, C.; Federico, A.; Trappoliere, M.; Tuccillo, C.; De Sio, I.; Di Leva, A.; Niosi, M.; D’Auria, M.V.; Capasso, R.; Blanco, C.D.V. The effect of a silybin-vitamin e-phospholipid complex on nonalcoholic fatty liver disease: A pilot study. Dig. Dis. Sci. 2007, 52, 2387-2395. [CrossRef]

73. Bares, J.M.; Berger, J.; Nelson, J.E.; Messner, D.J.; Schildt, S.; Standish, L.J.; Kowdley, K.V. Silybin treatment is associated with reduction in serum ferritin in patients with chronic hepatitis C. J. Clin. Gastroenterol. 2008, 42, 937-944. [CrossRef]

74. Flaig, T.W.; Gustafson, D.L.; Su, L.-J.; Zirrolli, J.A.; Crighton, F.; Harrison, G.S.; Pierson, A.S.; Agarwal, R.; Glodé, L.M. A phase i and pharmacokinetic study of silybin-phytosome in prostate cancer patients. Investig. New Drugs 2007, 25, 139-146. [CrossRef]

75. Bombardelli, E.; Della Loggia, R.; Sosa, S.; Spelta, M.; Tubaro, A. Aging skin: Protective effect of silymarin-phytosome (r). Fitoterapia 1991, 62, 115-122.

76. He, C.; Yin, L.; Tang, C.; Yin, C. Size-dependent absorption mechanism of polymeric nanoparticles for oral delivery of protein drugs. Biomaterials 2012, 33, 8569-8578. [CrossRef]

77. Jani, P.; Halbert, G.W.; Langridge, J.; Florence, A.T. Nanoparticle uptake by the rat gastrointestinal mucosa: Quantitation and particle size dependency. J. Pharm. Pharmacol. 1990, 42, 821-826. [CrossRef] [PubMed]

78. Hussain, N.; Jaitley, V.; Florence, A.T. Recent advances in the understanding of uptake of microparticulates across the gastrointestinal lymphatics. Adv. Drug Deliv. Rev. 2001, 50, 107-142. [CrossRef]

79. Parthasarathi, S.; Muthukumar, S.P.; Anandharamakrishnan, C. The influence of droplet size on the stability, in vivo digestion, and oral bioavailability of vitamin e emulsions. Food Funct. 2016, 7, 2294-2302. [CrossRef] [PubMed]

80. Ha, T.V.; Kim, S.; Choi, Y.; Kwak, H.S.; Lee, S.J.; Wen, J.; Oey, I.; Ko, S. Antioxidant activity and bioaccessibility of size-different nanoemulsions for lycopene-enriched tomato extract. Food Chem. 2015, 178, 115-121. [CrossRef] [PubMed]

81. Lethuaut, L.; Metro, F.; Genot, C. Effect of droplet size on lipid oxidation rates of oil-in-water emulsions stabilized by protein. J. Am. Oil Chem. Soc. 2002, 79, 425-430. [CrossRef]

82. Solans, C.; Izquierdo, P.; Nolla, J.; Azemar, N.; Garcia-Celma, M.J. Nano-emulsions. Curr. Opin. Colloid 2005, 10, 102-110. [CrossRef]

83. Verma, A.; Stellacci, F. Effect of surface properties on nanoparticle-cell interactions. Small 2010, 6, 12-21. [CrossRef] [PubMed] 
84. Koppel, D.E. Analysis of macromolecular polydispersity in intensity correlation spectroscopy-Method of cumulants. J. Chem. Phys. 1972, 57, 4814-4820. [CrossRef]

85. Zhang, L.; Han, L.; Sun, X.; Gao, D.; Qin, J.; Wang, J. The use of pegylated liposomes to prolong the circulation lifetime of salvianolic acid b. Fitoterapia 2012, 83, 678-689. [CrossRef] [PubMed]

86. Li, W.; Yi, S.; Wang, Z.; Chen, S.; Xin, S.; Xie, J.; Zhao, C. Self-nanoemulsifying drug delivery system of persimmon leaf extract: Optimization and bioavailability studies. Int. J. Pharm. 2011, 420, 161-171. [CrossRef] [PubMed]

87. Puttipipatkhachorn, S.; Nunthanid, J.; Yamamoto, K.; Peck, G. Drug physical state and drug-polymer interaction on drug release from chitosan matrix films. J. Control. Release 2001, 75, 143-153. [CrossRef]

88. Patil, S.; Sandberg, A.; Heckert, E.; Self, W.; Seal, S. Protein adsorption and cellular uptake of cerium oxide nanoparticles as a function of zeta potential. Biomaterials 2007, 28, 4600-4607. [CrossRef] [PubMed]

89. Prokop, A.; Kozlov, E.; Carlesso, G.; Davidson, J.M. Hydrogel-Based Colloidal Polymeric System for Protein and Drug Delivery: Physical and Chemical Characterization, Permeability Control and Applications. In Filled Elastomers Drug Delivery Systems; Springer: Berlin, Germany, 2002; pp. 119-173.

90. Unger, F.; Wittmar, M.; Kissel, T. Branched polyesters based on poly[vinyl-3-(dialkylamino)alkylcarbamateco-vinyl acetate-co-vinyl alcohol]-graft-poly(D,L-lactide-co-glycolide): Effects of polymer structure on cytotoxicity. Biomaterials 2007, 28, 1610-1619. [CrossRef] [PubMed]

91. Shyam, K.R.; Kumar, G.M. Prepration, charactaerization and antioxidant activities of gallic acid-phospholipids complex. Int. J. Res. Pharm. Sci. 2012, 2, 138-148.

92. Maiti, K.; Mukherjee, K.; Gantait, A.; Saha, B.P.; Mukherjee, P.K. Curcumin-phospholipid complex: Preparation, therapeutic evaluation and pharmacokinetic study in rats. Int. J. Pharm. 2007, 330, 155-163. [CrossRef]

93. Naik, S.R.; Panda, V.S. Hepatoprotective effect of ginkgoselect phytosome in rifampicin induced liver injury in rats: Evidence of antioxidant activity. Fitoterapia 2008, 79, 439-445. [CrossRef] [PubMed]

(C) 2019 by the authors. Licensee MDPI, Basel, Switzerland. This article is an open access article distributed under the terms and conditions of the Creative Commons Attribution (CC BY) license (http://creativecommons.org/licenses/by/4.0/). 